\title{
PAMAM dendrimers: blood- brain barrier transport and neuronal uptake after focal brain ischemia
}

\author{
Sofia D. Santos ${ }^{a, b, 1}$, Miguel Xaviera,b,1, Diana M.

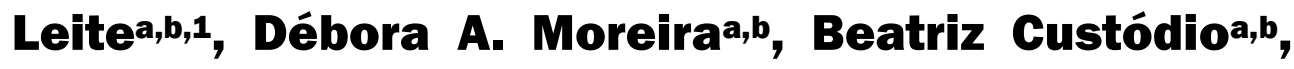 \\ Marília Torradoa,b, Rita Castroc, Victoria Leiroa,b, João \\ Rodriguesc, Helena Tomásc, Ana P. Pêgoa,b,d,e,*
}

\author{
a $i_{3} S$ - Instituto de Investigacão e Inovacão em Saude, Universidade do Porto, Rua Alfredo Allen, 208, \\ 4200-135 Porto, Portugal \\ b INEB - Instituto de Engenharia Biomedica, Universidade do Porto, Rua Alfredo Allen, 208, 4200-135 \\ Porto, Portugal \\ ' COM - Centro de Quimica da Madeira, MMRG, Universidade da Madeira, Campus Universitario da \\ Penteada, 9020-105 Funchal, Portugal \\ ${ }^{d}$ FEUP - Faculdade de Engenharia da Universidade do Porto, R. Dr. Roberto Frias s/n, 4200-465 Porto, \\ Portugal \\ e ICBAS - Instituto de Ciencias Biomedicas Abel Salazar, Universidade do Porto, R. de Jorge Viterbo \\ Ferreira, 228, 4050-313 Porto, Portugal \\ * Corresponding author at: INEB - Instituto de Engenharia Biomédica, Universidade do Porto, Rua \\ Alfredo Allen, 208, 4200-135 Porto, Portugal. \\ 1 These authors contributed equally to this work.
}

Originally published in J Control Release. 2018 Dec 10;291:65-79. doi: 10.1016/j.jconrel.2018.10.006.

\begin{abstract}
Drug delivery to the central nervous system is restricted by the blood-brain barrier (BBB). However, with the onset of stroke, the BBB becomes leaky, providing a window of opportunity to passively target the brain. Here, cationic poly(amido amine) (PAMAM) dendrimers of different generations were functionalized with poly(ethylene glycol) (PEG) to reduce cytotoxicity and prolong blood circulation half-life, aiming for a safe in vivo drug delivery system in a stroke scenario. Rhodamine $B$ isothiocyanate (RITC) was covalently tethered to the dendrimer backbone and used as a small surrogate drug as well as for tracking purposes.
\end{abstract}

The biocompatibility of PAMAM was markedly increased by PEGylation as a function of dendrimer generation and degree of functionalization. The PEGylated RITC-modified dendrimers did not affect the integrity of an in vitro BBB model. Additionally, the functionalized dendrimers remained safe when in contact with the bEnd. 3 cells and rat primary astrocytes composing the in vitro BBB model after hypoxia induced by oxygen-glucose deprivation. Modification with PEG also decreased the interaction and uptake by endothelial cells of PAMAM, indicating that the transport across a leaky 
BBB due to focal brain ischemia would be facilitated. Next, the functionalized dendrimers were tested in contact with red blood cells showing no haemolysis for the PEGylated PAMAM, in contrast to the unmodified dendrimer. Interestingly, the PEG-modified dendrimers reduced blood clotting, which may be an added beneficial function in the context of stroke.

The optimized PAMAM formulation was intravenously administered in mice after inducing permanent focal brain ischemia. Twenty-four hours after administration, dendrimers could be detected in the brain, including in neurons of the ischemic cortex.

Our results suggest that the proposed formulation has the potential for becoming a successful delivery vector for therapeutic application to the injured brain after stroke reaching the ischemic neurons.

\section{Graphical abstract}

(A) PEG-conjugated PAMAM dendrimers bound with RITC diffusing through a 'leaky' blood brain barrier upon focal cerebral ischemia. (B) Modified PAMAM dendrimer identified in neurons at the site of the brain ischemic injury.

A

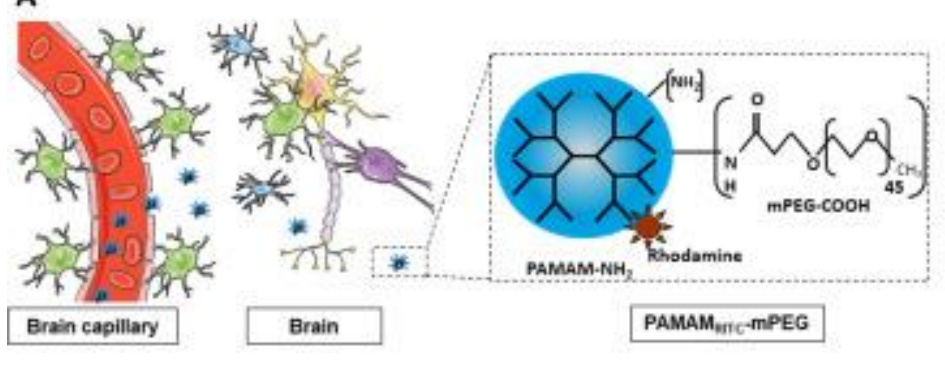

B

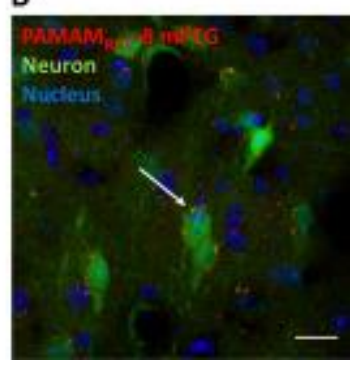

Keywords: Dendrimers; Poly(amido amine) PAMAM; Poly(ethylene glycol) PEG; Nanomaterials; Nanomedicine; Drug delivery; Blood-brain barrier; Brain ischemia; Stroke; In vivo

\section{INTRODUCTION}

Drug delivery to the central nervous system (CNS) remains a challenge. However, this is not due to the lack of therapeutic potential of existing drugs but to their restricted capacity to enter the CNS, which is protected from external threats by the blood brain barrier (BBB) [1]. The BBB is an active interface between the blood and the CNS and its main function is to maintain homeostasis of the latter. It consists of brain endothelial cells, which along with astrocytes, neurons and pericytes form the neurovascular unit (NVU). The barrier is characterized by the presence of intercellular tight junctions (TJ) and efflux transporters, being reported to block over $98 \%$ of all molecules from entering the brain [2].

Upon brain injury, as in stroke, fenestration of the BBB occurs, altering the CNS permeability [3]. This effect can be used in favour of CNS delivery research, as it opens a window of opportunity for passively targeting a therapeutic molecule to the compromised region of the brain following intravenous (i.v.) delivery. In stroke, the therapeutic options are limited to thrombolysis by the use of 
tissue plasminogen activator ( $\mathrm{tPa}$ ) or mechanical thrombectomy, which can only be applied to a small fraction of patients [4]. Efforts to use neuroprotectants have emerged [5] but their success is limited by the reduced amounts that reach the lesion as well as by the lack of cell specificity. Both of these drawbacks can be overcome by the use of delivery vectors, such as dendrimers [6] and hyperbranched polymers (HBP) [7]. These can prolong the blood circulation half-life of the candidate molecule $[7,8]$ and can be functionalized to have cell targeting specificity $[6,7,9]$ increasing the amount that reaches the brain. Within the nanomedicine field, these vectors have emerged as interesting carriers due to their structural features, such as their globular and highly branched nanostructure, and the presence of several terminal functional groups that can be explored to tether, in a specific manner, different ligands and/or drugs. Moreover, they are able to form complexes and/or encapsulate a variety of cargos. Through these strategies, the bioavailability and protection of the different carried cargos is increased, enhancing the likelihood of reaching the target tissue or cells. These features and versatility for drug transport have made these promising nanomaterials to be explored as vectors for both gene and drug delivery [[10], [11], [12], [13], [14]]. Additionally, dendrimers present further improved intrinsic structural characteristics. These include a welldegfined and controllable structure and a very low polydispersity, which make them one of the most powerful class of vectors for different biomedical applications.

Among the earliest proposed dendrimers, poly(amide amine) (PAMAM) [15] has been the most explored dendrimer for different applications due to their commercial availability [6]. However, one concern over the use of PAMAM in biological applications is their potential toxicity, especially in their cationic (amine-terminated) variant [[16], [17], [18]]. To overcome this issue, functionalization with poly(ethylene glycol) (PEG) has been successfully explored. PEG is a biocompatible polymer with a wide application in drug delivery. In the context of delivery to the CNS, the advantages of combining PAMAM with PEG are twofold: a) to decrease PAMAM toxicity and b) to decrease blood clearance by shielding the dendrimer and improving their delivery role [19]. The generation (G) of PAMAM dendrimers also affects biocompatibility. Increasing $G$ increases their multivalency, but it is also known to increase toxicity $[6,10,20]$. Therefore, a compromise between the highest possible $G$ and the least toxicity exerted in contact with cells should be reached. Obtaining these optimized PAMAM carriers, regarding the most appropriate $G$ and functionalization opens possibilities for its use in stroke and other brain injuries.

In this work, we report the modification and use of different generations ( $\mathrm{G}_{4}$ and $\mathrm{G} 6$ ) of PAMAM dendrimers, as well as their PEGylated derivatives with different degrees of functionalization $(4,8$ and 12 methoxy-terminated PEG, mPEG) aiming for its use in CNS delivery of a putative therapeutic molecule in a stroke scenario. A thorough analysis of the cytotoxicity of the conjugate, as well as its effect on an in vitro model of the BBB is presented before its application in vivo, using a mice model of permanent focal brain ischemia.

\section{Materials and methods}

\subsection{Materials}

Fourth and sixth-generation amine-terminated PAMAM ( $\mathrm{G}_{4}-\mathrm{NH}_{2}$ and $\mathrm{G} 6-\mathrm{NH}_{2}$, respectively) having ethylene diamine cores were purchased as $10-25 \%$ methanol solutions from Dendritech, Inc. (Midland, MI, USA). Methoxy-PEG-carboxylic acid (mPEG-COOH, MW $=2000$ ) was purchased from Yan Yi Biotechnology Co. Ltd. (Shanghai, China). 1-(3-Dimethylaminopropyl)-3-ethylcarbodiimide 
hydrochloride (EDC) was obtained from J \& K Scientific Ltd. (Beijing, China). Dialysis membranes were purchased from Spectrum Laboratories Inc. (Rancho Dominguez, CA, USA). Deuterium oxide (D2O) was obtained from ACROS Organics (Thermo Fisher Scientific, Geel, Belgium). Paraformaldehyde (PFA) was purchased from Merck KGaA (Darmstadt, Germany). Penicillin/streptomycin solution 100x (Pen/Strep) was obtained from BioWest SAS (Nuaillé, France). Ethylene diamine tetraacetic acid (EDTA) was purchased from VWR International (Leuven, Belgium). d-Glucose anhydrous was acquired from Fisher Scientific UK Ltd. (Loughborough, Leicestershire, UK). Dulbecco's modified eagle medium (DMEM) Glutamax ${ }^{\mathrm{TM}}$, Hank's balanced salt solution (HBSS) and normal goat serum [21] were obtained from Gibco ${ }^{\circledR}$ Life Technologies, Inc. (Grand Island, NY, USA). Imidazole, dimethyl sulfoxide (DMSO, HPLC grade), rhodamine B isothiocyanate (RITC), papain from papaya latex, trypsin, phosphate buffered saline (PBS), fetal bovine serum (FBS), rat-tail collagen type-I, resazurin sodium salt, sodium fluorescein $(\mathrm{NaF}, \mathrm{Mw}=376 \mathrm{Da})$, Triton $^{\mathrm{TM}}-\mathrm{X}-100,4^{\prime}$ ,6-Diamidino-2-phenylindole di-hydrochloride (DAPI) and fluoromount ${ }^{\mathrm{TM}}$ aqueous mounting medium were purchased from Sigma-Aldrich (St. Louis, MO, USA). Sodium cacodylate buffer, glutaraldehyde (electron microscopy grade), osmium tetraoxide, uranyl acetate, Epon ${ }^{\mathrm{TM}}-812$ resin and Reynold's lead citrate solution were obtained from Electron Microscopy Sciences (Hatfield, PA, USA).

Unless mentioned otherwise, all reagents were used as received and according to the manufacturer's recommendations.

\subsection{Animals}

Procedures involving animals and their care were conducted in compliance with institutional ethical guidelines (i3S animal facility) and in accordance with the National and European Union rules (EU Directive 2010/63/EU for animal experiments). All animal experiments for this research were approved by institute animal ethics committee (CEA, i3S) and the Portuguese Veterinary Authorities (DGAV, licence 0421/000/000/2017). Animals had free access to food and water, being kept under a 12-h light/12-h dark cycle at the izS animal facility.

\subsection{RITC-labelling of PAMAM dendrimers}

$\mathrm{G}_{4}$ and $\mathrm{G} 6$ PAMAM-NH2 dendrimers were labelled with RITC as previously described [22]. Amine groups from PAMAM-NH2 react with the isothiocyanate groups from RITC, yielding stable isothiourea bonds. Briefly a RITC solution (1.5 equiv) was added dropwise to a PAMAM-NH2 solution (1 equiv), both in dry DMSO, and the reaction mixture was magnetically stirred for $12 \mathrm{~h}$ at room temperature (RT), in the dark, and under an inert argon atmosphere (Scheme 1). The resulting mixture was transferred into a dialysis membrane (6000-8000 MWCO, RC) and purified for $48 \mathrm{~h}$ until free RITC could not be detected in the eluate. Finally, the resulting solution was freeze-dried yielding the PAMAM-RITC conjugates as a dark pink powder ( $93 \%$ yield), which were stored at $4^{\circ} \mathrm{C}$ until further use. The amount of RITC in the conjugate was quantified by UV-Vis spectroscopy at $560 \mathrm{~nm}$ using Quartz Suprasil ${ }^{\circledR}$ cuvettes (Hellma ${ }^{\circledR}$, Germany) and a Lambda 25 UV/Vis spectrophotometer (PerkinEImer, MA, USA).

\subsection{Conjugation of methoxy-PEG2000 to PAMAM dendrimers}


Amine groups from PAMAM-RITC react with the carboxylic acid from $\mathrm{MPEG}$, yielding stable amide bonds. $\mathrm{G}_{4}$ and $\mathrm{G} 6$ PAMAM-RITC were reacted with different molar ratios of mPEG-COOH $(4,8$ and 12 equiv), adapting previously reported methods [23]. The MPEG chains were activated by the addition of EDC. $\mathrm{HCl}$ (5 equiv) to $\mathrm{mPEG}$ ( 1 equiv), both in $0.1 \mathrm{M}$ imidazole solutions at $\mathrm{pH}$. The solution was magnetically stirred for $3 \mathrm{~h}$ at RT. The resulting o-acylisourea was added to a solution of PAMAM-RITC in ultra-pure water, under vigorous agitation. The reaction mixture was magnetically stirred for $48 \mathrm{~h}$ at RT (Scheme 1). The resulting solution was transferred into a dialysis membrane (6000-8000 MWCO, RC), purified to remove any unreacted MPEG for 3 days, and freeze-dried to obtain the PEG-PAMAM-RITC conjugates as dark pink foaming solids ( $91 \%$ yield), which were stored at $4^{\circ} \mathrm{C}$ until further use. The PEGylation degree was determined by $1 \mathrm{H}$ NMR using a Bruker $400 \mathrm{MHz}$ Avance II+ NMR spectrometer in $\mathrm{D}_{2} \mathrm{O}$. Chemical shifts are reported in ppm ( $\delta$ units) and referenced to tetramethylsilane (TMS) as the internal standard.

\subsection{Size and Zeta potential of the G4 PAMAMrITC 8mPEG dendrimers}

The hydrodynamic diameter (size) and surface charge (zeta potential) of $\mathrm{G}_{4}$ PAMAM RITC $_{\text {PmPEG }}$ dendrimers were measured using a Zetasizer ZS nanoseries (Malvern, UK). All dendrimer solutions were dissolved in saline ( $0.9 \% \mathrm{w} / \mathrm{v}$ sodium chloride) at $1.2 \mathrm{mg} / \mathrm{ml}$. The solutions were freshly prepared before dynamic light scattering (DLS) measurements with vortexing (10 s) after dissolution as well as before analysis. Measurements were performed at $633 \mathrm{~nm}$ with a detection angle of $173^{\circ}$, at $25^{\circ} \mathrm{C}$ and with an equilibration time of $60 \mathrm{~s}$. Each measurement was performed in triplicate by the equipment. The Smoluchowski model was applied for zeta potential determination and cumulant analysis was used for mean particle size determination by volume. The presented data are expressed as the mean $\pm \mathrm{SD}$ of four independent sample preparations and measurements.

\subsection{Rat primary astrocytes isolation}

Rat primary astrocytes were obtained as previously described [24] from the cerebral cortices of 2 days-old Wistar Han rats. The meninges and blood vessel were removed and the isolated cortices were digested for 30 min in HBSS without calcium and magnesium supplemented with papain $(0.2 \mathrm{U} / \mathrm{ml})$. The dissociated cells were cultured in $75 \mathrm{~cm} 2$ culture flasks and maintained in DMEM Glutamax $^{\mathrm{TM}}$ supplemented with $10 \%\left(\mathrm{v} / \mathrm{v}\right.$ ) heat inactivated (30 min, $56^{\circ} \mathrm{C}$ ) FBS and $1 \%(\mathrm{v} / \mathrm{v})$ Pen/Strep. At confluency, approximately 12 days after beginning of culture, the culture flasks were shaken overnight (240 rpm) at $37^{\circ} \mathrm{C}$ to remove any loosely attached microglia, oligodendrocyte progenitors and neurons. After removal of the detached cells, astrocytes were sub-cultured in $75 \mathrm{~cm} 2$ culture flasks.

\subsection{Cell culture}

Rat primary astrocytes (passages 3-7) and immortalised mouse brain endothelial cells, bEnd.3 (passages 2-15), were cultured in DMEM Glutamax ${ }^{\mathrm{TM}}$ supplemented with $10 \%(\mathrm{v} / \mathrm{v})$ heat inactivated FBS and $1 \%(v / v)$ Pen/Strep. Cells were maintained in a humidified chamber at $37^{\circ} \mathrm{C}$ and $5 \% \mathrm{CO}_{2}$. Media was replenished every $2-3$ days and cells were routinely sub-cultured using a $0.25 \%$ trypsin/EDTA solution, at a maximum confluency of $70-80 \%$.

\subsection{In-vitro cytotoxicity assay}


The cytotoxicity of PAMAM-RITC was determined indirectly by the resazurin reduction assay [25]. bEnd. 3 cells and rat primary astrocytes were plated in 96 -well plates at densities of $2.5 \times 105$ viable cells/cm2 and $5 \times 104$ viable cells/cm2, respectively. After $24 \mathrm{~h}$, the media was changed and $\mathrm{G} 4 / \mathrm{G} 6$, unmodified or mPEG-modified PAMAM-RITC in ultrapure deionized water were added to yield the final concentrations of $0.01,0.1$ and $1 \mathrm{mg} / \mathrm{ml}$. Ultrapure water was used as control. The cells were incubated for $24 \mathrm{~h}$, the media was replenished with fresh DMEM supplemented with $10 \%(\mathrm{v} / \mathrm{v})$ resazurin solution, and further incubated for $3 \mathrm{~h}$ at $37^{\circ} \mathrm{C}$. Cell metabolic activity was determined by measuring the fluorescence of resofurin $(\lambda e x=560 \mathrm{~nm}, \lambda e m=590 \mathrm{~nm})$ using black microassay 96 well plates (Greiner bio-one) and a BioTeK ${ }^{\circledR}$ Synergy MX (Winnoski, VT, USA) multi-plate reader. Each assay was repeated independently at least twice and with three experimental replicates. The results are expressed as a percentage in relation to the control.

\subsection{Cytotoxicity in conditions of oxygen-glucose deprivation (OGD)}

The cytotoxicity of $\mathrm{G}_{4}$ PAMAM RITC-8mPEGon hypoxic cultures (induced by oxygen-glucose deprivation, $O G D$ ) was determined indirectly using the resazurin reduction assay. Primary rat astrocytes and bEnd. 3 cells were seeded on poly(l-lysine) (PDL) or collagen-coated 96 -well plates at densities of $4.0 \times 104$ viable cells/cm2 and $1.0 \times 105$ viable cells/cm2 respectively, $24 \mathrm{~h}$ before use. On the following day, the cultures were rinsed once with warm HBSS and deoxygenated HBSS without glucose and serum was added to each well. The plate was incubated in a humidified chamber at $37^{\circ} \mathrm{C}$, $0.1 \% \mathrm{O}_{2}$ and $5 \% \mathrm{CO}_{2}$ for $4 \mathrm{~h}$. Normoxia conditions were followed as a control. After $4 \mathrm{~h}$ of OGD, cells were rinsed once with warm HBSS and $100 \mu \mathrm{L}$ of $\mathrm{G}_{4}$ PAMAM $\mathrm{RIT}-8 \mathrm{mPEG}$ in HBSS $(0.01 \mathrm{mg} / \mathrm{ml})$ were added. After 4 or $24 \mathrm{~h}$ of exposure, the HBSS was removed and replaced by fresh DMEM Glutamax ${ }^{\mathrm{TM}}$ supplemented with $10 \%(\mathrm{v} / \mathrm{v})$ heat-inactivated serum, $1 \%(\mathrm{v} / \mathrm{v})$ Pen/Strep and $10 \%(\mathrm{v} / \mathrm{v})$ resazurin solution. After $2 \mathrm{~h}, 100 \mu \mathrm{L}$ were transferred to black microassay 96 -well plates and fluorescence was measured $(\lambda$ exc $=530 \mathrm{~nm} ; \lambda$ em $=590 \mathrm{~nm})$ as described in 2.8. Cells not exposed to G4 PAMAM RITC$8 \mathrm{mPEG}$ were used as a control and all experiments were done in triplicate.

\subsection{In vitro BBB model}

An in vitro BBB model was established as previously reported [26]. Briefly, $0.4-\mu m$ pore-size transwell ${ }^{\circledR}$ were coated with collagen type-I $(10 \mu \mathrm{g} / \mathrm{cm} 2)$ and primary rat astrocytes were seeded onto the basolateral side of the membrane at $5.0 \times 104$ viable cells $/ \mathrm{cm} 2$. The cells were allowed to adhere and the inserts were inverted back into 24 -well plates. The astrocytes were expanded in DMEM Glutamax ${ }^{\mathrm{TM}}$ supplemented with $10 \%(\mathrm{v} / \mathrm{v})$ heat inactivated FBS and $1 \%(\mathrm{v} / \mathrm{v})$ Pen/Strep. After two days, bEnd. 3 cells were seeded onto the apical side at $2.5 \times 105$ viable cells/cm2 and co-cultured for 11 days. Half of the medium from both the apical and basolateral compartments was changed every day.

\subsubsection{Transepithelial electrical resistance (TEER)}

The transepithelial electrical resistance (TEER) was measured to assess barrier integrity, following a protocol for static epithelial models (Gaillard and de Boer, 2000). The cell-cultures inserts were allowed to equilibrate to RT for $10 \mathrm{~min}$ and the TEER was measured using Millicell ${ }^{\circledR}$ ERS-2 (Merck Millipore, Billerica, MA, USA) chopstick electrodes. TEER values in $\Omega . c m 2$ were calculated for each 
condition by subtracting the TEER reading of empty transwells ${ }^{\circledR}$ in PBS to the cell-cultured transwell inserts, and multiplying by the surface area of the well.

\subsubsection{Fluorescein leakage assay}

The permeability of the established in vitro BBB model to small molecules was assessed by a fluorescein ( $\mathrm{NaF}$ ) leakage test [27]. At day 11 of co-culture, when the TEER was found to be highest, the transwell ${ }^{\circledR}$ inserts were rinsed with warm HBSS and transferred to 24 -well plates containing $600 \mu \mathrm{L}$ of warm HBSS per well. The transwells ${ }^{\circledR}$ were evenly distributed within each condition based on the measured TEER values. NaF diluted in HBSS at $100 \mu \mathrm{g} / \mathrm{ml}$ was loaded to the apical

$$
\begin{aligned}
& \text { Cleared Volume }(\mu L)=\frac{C_{\text {basolateral }} \times V_{\text {apical }}}{C_{\text {apical }}} \\
& P_{e}=\frac{\frac{1}{\mathrm{PS}_{\text {app }}}-\frac{1}{\mathrm{PS}_{\text {insert }}}}{\text { insert surface area }}
\end{aligned}
$$

compartment of the transwells ${ }^{\circledR}$ and at predetermined time-points $(15,30,45$ and $60 \mathrm{~min}) 100 \mu \mathrm{L}$ were collected from the basolateral chamber and replenished with fresh HBSS. The concentration of $\mathrm{NaF}$ in the basolateral chamber was determined by fluorescence spectroscopy ( $\lambda$ ex $=485 \mathrm{~nm}$, $\lambda e m=535 \mathrm{~nm}$ ) using a BioTek ${ }^{\circledR}$ Synergy MX (USA) multi-plate reader. The cumulative transport of $\mathrm{NaF}$ was expressed as the volume of donor solution that was cleared to the basolateral chamber at each time-point using Eq. (1), where Cbasolateral is the concentration of $\mathrm{NaF}$ in the basolateral chamber at each time-point and Vapical and Capical the volume and concentration of the added $\mathrm{NaF}$ solution.

The cumulative transport as a function of time was determined by linear regression and the permeability coefficients ( $\mathrm{cm} / \mathrm{s}$ ) were calculated according to Eq. (2), where Pe is the permeability coefficient $(\mathrm{cm} / \mathrm{s})$, and PSapp and PSinsert are the NaF cumulative transports through the cellcultured and cell-free inserts receptively, over time $(\mu \mathrm{L} / \mathrm{s})$.

\subsubsection{Tight junction immunocytochemistry}

At day 11 of co-culture, cells were fixed on both sides of the transwell ${ }^{\circledR}$ membranes using a $3.7 \%(\mathrm{w} / \mathrm{v})$ PFA solution in PBS for 15 min at RT. For the immunostaining of claudin-5, cells were permeabilized with $0.2 \%(\mathrm{w} / \mathrm{V})$ Triton-X-100 and non-specific binding was blocked by incubation in $10 \%(\mathrm{v} / \mathrm{v})$ FBS in PBS, for $1 \mathrm{~h}$. The membranes were then incubated with Alexa-Fluor ${ }^{\circledR}$ 488-conjugated claudin- 5 monoclonal antibody (1:100, Novex ${ }^{\circledR}$, Life Technologies) in PBS with $5 \%(v / v)$ FBS, for 2 h at RT.

For the immunostaining of zonnula occludens-1 (ZO-1), cells were permeabilized with $0.05 \%(\mathrm{w} / \mathrm{v})$ Triton-X-100 and non-specific binding was blocked by incubation with $5 \%(v / v)$ NGS in PBS, for $1 \mathrm{~h}$. The membranes were then incubated with a ZO-1 rabbit polyclonal IgG antibody (1:100, Novex ${ }^{\circledR}$, Life Technologies) in PBS with $1 \%(\mathrm{v} / \mathrm{v})$ NGS overnight, at $4{ }^{\circ} \mathrm{C}$ followed by incubation with Alexa Fluor ${ }^{\circledR}$ 488 goat anti-rabbit IgG $(H+L)$ antibody (1:500, Molecular Probes ${ }^{\circledR}$, Life Technologies) in PBS, for $2 \mathrm{~h}$ at RT. 
For both stainings, the nuclei were counterstained by incubation with DAPI $(0.1 \mu \mathrm{g} / \mathrm{ml})$ for $10 \mathrm{~min}$ at RT. The transwell ${ }^{\circledR}$ membranes were mounted using Fluoromount ${ }^{\mathrm{TM}}$ mounting medium and imaged with a confocal laser scanning TCS SP 5 microscope (63× oil objective; Leica Microsystems, Germany).

\subsubsection{Transmission electron microscopy}

Cells on both sides of the transwell ${ }^{\circledR}$ membranes were fixed in $2 \%(\mathrm{v} / \mathrm{v})$ glutaraldehyde in cacodylate buffer ( $\mathrm{pH} 7.2$ ) for $30 \mathrm{~min}$ followed by $1 \%(\mathrm{v} / \mathrm{v})$ osmium tetroxide $\left(\mathrm{OsO}_{4}\right)$ in cacodylate buffer for $2 \mathrm{~h}$. The membranes were stained en bloc with a $0.5 \%(\mathrm{v} / \mathrm{v})$ uranyl acetate solution at $4{ }^{\circ} \mathrm{C}$ overnight and dehydrated in graded ethanol. After carrying the membranes through propylene oxide, the membranes were embedded in Epon ${ }^{\mathrm{TM}}-812$ resin and polymerized at $60^{\circ} \mathrm{C}$ for $48 \mathrm{~h}$. Semi-thin and ultra-thin sections were cut perpendicularly to the membrane using an ultra-microtome (Leica Reichert Supernova), placed on 200-mesh copper grids and stained in $5 \%(\mathrm{v} / \mathrm{v})$ uranyl acetate and $0.8 \%(\mathrm{v} / \mathrm{v})$ Reynold's lead citrate solutions for 5 and $10 \mathrm{~min}$ respectively. The samples were analysed using a transmission electron microscope (JEM-1400, Jeol, Tokyo, Japan) and an Orius ${ }^{\circledR}$ Sc100oCCD Digital Camera (Gatan, Pleasanton, CA, USA).

\subsubsection{Hypoxia induction in the in vitro BBB model - OGD}

To mimic the scenario of an hypoxic BBB, an in vitro BBB model was set-up as above and exposed to oxygen and glucose deprivation (OGD) conditions. On day 7, the TEER was measured and the media was changed to deoxygenated HBSS without glucose and serum. The constructs were incubated in a humidified chamber at $37^{\circ} \mathrm{C}, 0.1 \% \mathrm{O}_{2}$ and $5 \% \mathrm{CO}_{2}$ (hypoxia chamber) for $4 \mathrm{~h}$. As a control, equivalent cultures were maintained in a humidified chamber at $37^{\circ} \mathrm{C}$ and $5 \% \mathrm{CO}_{2}$.

\subsection{Effect of PAMAM on the integrity of the in vitro BBB model in normoxia and hypoxia}

The effect of PAMAM on the BBB model was assessed by monitoring the TEER during incubation with the PAMAM conjugates. The TEER was measured at to and PAMAM were added to the apical compartment yielding a final concentration of $0.01 \mathrm{mg} / \mathrm{ml}$. Incubation was carried out at $37^{\circ} \mathrm{C}$ in a humidified chamber and every hour the TEER was measured, as described in Section 2.10.1. The TEER of barriers treated with $1 \%(\mathrm{w} / \mathrm{v})$ SDS detergent was used as positive control and untreated cells were used as baseline control.

To assess the effect of PAMAM on a hypoxic BBB, after $4 \mathrm{~h}$ of $O G D$, the cells were rinsed with warm HBSS and fresh HBSS was added to the inserts and wells. The barrier integrity was verified by measuring the TEER and a $\mathrm{G}_{4}$ PAMAM RITC- PmPEGsolution was added to the apical compartment yielding a concentration of $0.01 \mathrm{mg} / \mathrm{ml}$. The cells were placed in a humidified chamber at $37^{\circ} \mathrm{C}$ and $5 \% \mathrm{CO}_{2}$ and the TEER was measured every hour, in triplicate, for each condition.

To determine changes in the permeability of the barrier, after $4 \mathrm{~h}$ of OGD, the cells were rinsed with warm HBSS and $1 \mathrm{ml}$ of $\mathrm{G}_{4}$ PAMAMRITC-8mPEGHBSS $(0.01 \mathrm{mg} / \mathrm{ml})$ was added to the apical compartment. After $1 \mathrm{~h}$, the cells were rinsed and transferred to wells with $1 \mathrm{ml} \mathrm{HBSS}$. A $100 \mu \mathrm{g} / \mathrm{ml}$ $\mathrm{NaF}$ solution in HBSS was added to the apical chamber. After $30 \mathrm{~min}$, the inserts were removed and the concentration of $\mathrm{NaF}$ concentration in the basolateral chamber was determined as described in Section 2.10.2. 


\subsection{Transport across the BBB}

To evaluate the ability of PAMAM-RITC to cross the BBB in both normoxia and hypoxia, the transwells ${ }^{\circledR}$ were distributed evenly, based on TEER, into 24 -well plates containing $800 \mu \mathrm{L}$ of warm DMEM per well. Hypoxia induction was performed as described above. After, PAMAM-RITC were loaded to the apical compartment yielding a final concentration of $0.01 \mathrm{mg} / \mathrm{ml}$. Cells were incubated in a humidified chamber at $37^{\circ} \mathrm{C}$ for $1 \mathrm{~h}$. After, the medium from the abluminal side was collected and the PAMAM-RITC fluorescence was quantified by fluorescence spectroscopy (spectrofluorometer Fluoromax-4, Horiba) $(\lambda e x c=552 \mathrm{~nm} ; \lambda e m=598 \mathrm{~nm})$. A calibration curve was done measuring the fluorescence of successive dilutions of the dendrimer in medium. In a separate set of experiments, cells were imaged at $4 \mathrm{~h}$ and $24 \mathrm{~h}$ after PAMAM-RITC incubation. At the first time-point, the cells were rinsed with warm HBSS and fixed in a $3.7 \%$ (w/v) PFA solution for $15 \mathrm{~min}$ at RT. For the $24-\mathrm{h}$ time-point, at $4 \mathrm{~h}$ incubation, the dendrimers were removed by replenishing the media and cells were further cultured overnight before fixation. Cells were stained using Alexa Fluor ${ }^{\circledR} 488$ phalloidin (Molecular Probes ${ }^{\circledR}$, Life Technologies), counterstained with Hoechst 33342 (Molecular Probes ${ }^{\circledR}$, Life Technologies) and imaged using a TCS SP 5 microscope (Leica Microsystems, Germany) and a $63 \times$ oil objective.

\subsection{Uptake of PAMAM-RITC by bEnd.3 cells}

bEnd. 3 cells were cultured in 96 -well plates at $2.5 \times 105$ cells $/ \mathrm{cm} 2$ for $24 \mathrm{~h}$ before use. PAMAM-RITC were added to each well to yield a final concentration of $0.01 \mathrm{mg} / \mathrm{ml}$, and incubated for $4 \mathrm{~h}$ at $37^{\circ} \mathrm{C}$. Cells were washed with cold PBS to stop the cellular uptake and remove membrane-adhered dendrimers. Finally, cells were trypsinized and dendrimer uptake was quantified by flow cytometry using a BD FACSCalibur cytometer (Becton Dickinson, Franklin Lanes, NJ, USA).

\subsection{Hemolysis assay}

Human red blood cells (RBC) were isolated from buffy coats obtained from healthy volunteers (Centro Hospitalar de São João, EPE, Porto, Portugal) and processed to obtain RBC by density centrifugation with Histopaque ${ }^{\circledR}-1077$ from Sigma-Aldrich Co. (St. Louis, MO, USA) as reported previously [28]. After removal of the upper layer containing plasma and white blood cells, the layer containing RBC was washed three times in PBS. The purified RBC were diluted to $2.5 \times 109$ cells $/ \mathrm{ml}$ (similar to the concentration in blood) in PBS and $100 \mu \mathrm{L}$ were distributed in triplicate to a 96 round bottom well polypropylene microtiter plate. $\mathrm{G}_{4}$ PAMAM and $\mathrm{G}_{4}$ PAMAMRITC-8mPEG dilutions were prepared in a $0.9 \%(\mathrm{w} / \mathrm{v}) \mathrm{NaCl}$ solution. After 1,3 or $24 \mathrm{~h}$ incubation at $37^{\circ} \mathrm{C}$ under $5 \% \mathrm{CO}_{2}$, cells were centrifuged at $900 \mathrm{~g}$ for $10 \mathrm{~min}$ and $80 \mu \mathrm{L}$ of the supernatant was transferred to a 96 -well plate. The absorbance was determined at 380,415 and $450 \mathrm{~nm}$ using a multiplate reader (BioTeK ${ }^{\circledR}$ Synergy MX). Cells treated with the $0.9 \%(\mathrm{w} / \mathrm{v}) \mathrm{NaCl}$ solution or $1 \%(\mathrm{w} / \mathrm{v})$ Triton $\mathrm{X}-100$ were used as negative and positive control, respectively. The amount of hemoglobin $(\mathrm{Hb})$ released was calculated as follows: $\left[2 \times A_{41} 15 n m-\left(A_{3} 80 n m+A_{45} 0 n m\right)\right] /(E)$, where $A_{41} n_{n m}$ is the Soret band absorption of $\mathrm{Hb}$ and $\mathrm{A} 380 \mathrm{~nm}, \mathrm{~A} 45 \mathrm{onm}$ are correction factors of uroporphyrin which absorption falls under the same wavelength range. $E$ is the molar absorptivity of oxyhemoglobin at $415 \mathrm{~nm}$, which is equal to 79.46 . The percentage hemolysis was calculated as: Hemolysis $(\%)=\mathrm{Hb}$ value of sample/Total $\mathrm{Hb}$ value $\mathrm{x}$ 100, where total $\mathrm{Hb}$ value corresponds to $100 \%$ hemolysis with $1 \%(\mathrm{w} / \mathrm{v})$ Triton. In parallel, G4 PAMAM in $0.9 \%(\mathrm{w} / \mathrm{v}) \mathrm{NaCl}$ solution were measured in all concentrations to verify that the dendrimers did not contribute to the absorbance values. 


\subsection{Clotting time}

The impact of $\mathrm{G}_{4}$ PAMAM on coagulation was studied by a clotting assay. Normal human plasma was obtained from healthy volunteers (Centro Hospitalar de São João, EPE, Porto, Portugal). Aliquots were stored at $-20^{\circ} \mathrm{C}$ until use. The different concentrations of $\mathrm{G}_{4}$ PAMAM dendrimers freshly dissolved in saline $(0.9 \%(\mathrm{w} / \mathrm{v}) \mathrm{NaCl}$ solution) and the reference control (saline only) were added to the wells of a 96 -well plate. Glass coverslips with saline were included as a positive control. Calcium chloride was added to the thawed plasma, to a final concentration of $20 \mathrm{mM}$, to initiate clotting. Immediately, recalcified plasma was vortexed and added to the 96 -well plate. The plate was measured every minute with a multiplate reader (Biotek ${ }^{\circledR}$ Synergy $\mathrm{Mx}$ ) by a kinetic assay using absorbance at $405 \mathrm{~nm}$. The clot times were identified when the absorbance reached a maximal level.

\subsection{Focal brain ischemia model}

Adult, male mice (10-14 weeks), on a $\mathrm{C}_{57} \mathrm{BL} / 6 \mathrm{~J}$ background were used for this study. The animals were bred at the $i_{3} S$ animal facility and housed as stated above. All efforts were made to minimize animal suffering and the Russel and Burch $3 R^{2}$ 's principle was followed in the experimental study. The genetic background of the mice was altered to express yellow fluorescent protein (YFP) under the transcriptional control of the neuronal promoter Thy1 [29]. Line H (named SLICK-H), which showed a significant proportion of fluorescent neurons in the brain, was used.

A permanent occlusion of the distal part of the left middle cerebral artery (PMCAO) was performed to induce focal cerebral ischemia as described before [30]. Mice were selected in a random and blinded way. The animals received a mixture of fentanyl ( $0.05 \mathrm{mg} / \mathrm{kg})$, medetomidine $(0.5 \mathrm{mg} / \mathrm{kg})$ and midazolam $(5 \mathrm{mg} / \mathrm{kg})$ by intraperitoneal injections and placed on a heating pad. Under a stereomicroscope (Leica, Germany), a small craniotomy was made with a o.8-mm burr above the distal branch of the MCA using a high-speed microdrill. Electrocoagulation was applied to occlude permanently the artery, distally to its origin using an ERBE ICC 50 electrosurgical unit (Erbe medical, UK). Following surgery and post-surgical procedures, mice were intravenous (i.v.) administered in the tail vein with $\mathrm{G}_{4}$ PAMAM-RITC (10 mg/kg) or with the same molar amount of RITC. Control mice without surgery or sham control with surgery but without occlusion were administered in the same way with $\mathrm{G}_{4}$ PAMAM-RITC or with free RITC. Both compounds were dissolved, in physiological saline solution $(0.9 \% \mathrm{NaCl})$ on the day of administration. Mice were then kept at $28^{\circ} \mathrm{C}$ for $24 \mathrm{~h}$, under analgesia with buprenorphine (1 mg/kg), after which they were sacrificed for analysis.

\subsection{Processing of brain, kidney and urine}

To collect blood and urine, mice were handled $1 \mathrm{~h}$ and $24 \mathrm{~h}$ after surgery/administration. Urine was collected to an eppendorf by stimulating the bladder and frozen in dry ice. Blood was extracted from the tail using a heparinized capillary tube to an eppendorf coated with heparin and centrifuged for $10 \mathrm{~min}$ at $1000 \mathrm{rpm}$. The plasma supernatant was frozen in dry ice and stored at $-20^{\circ} \mathrm{C}$ until analysis.

To remove the brain and kidney, mice were anaesthetized with pentobarbital $(50 \mathrm{mg} / \mathrm{kg}$ ) for transcardial perfusion with PBS. Perfusion-fixated brains and kidneys were post-fixed in PFA for an additional $1-3 \mathrm{~h}$ and placed in $30 \%(\mathrm{w} / \mathrm{v})$ sucrose for $24 \mathrm{~h}$ at $4^{\circ} \mathrm{C}$, embedded in OCT (Thermo Scientific), frozen with liquid $\mathrm{N}_{2}$ and stored at $-20^{\circ} \mathrm{C}$ until sectioning. Brains were sectioned coronally into 10-12 parallel series of $20 \mu \mathrm{m}$ thick sections and kidneys into 6 parallel series of $20 \mu \mathrm{m}$ 
thick sections, using a Leica cryostat. For bioimaging analysis, tissue sections (brain and kidney) were counterstained with DAPI at $10 \mu \mathrm{g} / \mathrm{ml}$ for $15 \mathrm{~min}$.

\subsection{RITC fluorescence intensity measurements}

Brain and kidney: 10-12 brain sections from each animal, spanning the whole infarct tissue, and including the prefrontal cortex until the hippocampus were examined for RITC fluorescence intensity using an Axiovert $200 \mathrm{M}$ inverted fluorescent microscope (Zeiss, Germany) connected to a highresolution microscope digital Camera. 8-9 Images were obtained from the ipsilateral, the contralateral cortex or the uninjured cortex using constant microscope settings and camera exposure times. Images were quantified for fluorescence intensity in cortical layers IV, V and VI using the ImageJ software after adjusting the threshold and obtaining the integrated density. The thresholding tool settings were applied to all images.

Blood and Urine: 3 samples from each condition (free RITC and $\mathrm{G}_{4}$ PAMAMRITC-8mPEG) and each time point ( $1 \mathrm{~h}$ and $4 \mathrm{~h}$ ) were added to a black 96 -well plate and analysed by spectrofluorimetry in a multi-plate reader (BioTeK ${ }^{\circledR}$ Synergy MX) using $\lambda$ ex $=552 \mathrm{~nm}, \lambda e m=575 \mathrm{~nm}$ settings. Fluorescence was analysed in control blood and urine (without RITC administration) and in serial dilutions of free RITC.

\subsection{Statistical analysis}

Statistical analyses were performed using IBM SPSS software package (SPSS for Windows 22.0, IBM Corporation, Armonk, NY, USA) or GraphPad prism software (GraphPad Inc., California, USA). Data are presented as mean \pm standard deviation (SD). Independent student's t-test, one-way or two-way analysis of variance (ANOVA) statistical analysis were performed followed by Bonferroni's or Tukey's post-hoc tests to evaluate the significance of the experimental data. The significance level was set at 0.05 and $p$-values are indicated accordingly.

\section{Results and discussion}

\subsection{Labelling and PEGylation of PAMAM}

$\mathrm{G}_{4}$ and G6 PAMAM-NH2 were successfully labelled with RITC and PEGylated at different degrees (4, 8 and 12 mPEG chains) by reacting RITC and MPEG with their amine terminal groups to form stable isothiourea and amide bonds, respectively. The incorporation and quantification of RITC was determined by UV-Vis spectroscopy (see Table 1) indicating that both $\mathrm{G}_{4}$ and $\mathrm{G} 6-\mathrm{NH}_{2}$ were labelled with high efficiencies, obtaining molar ratios of 1.346 and 1.436, respectively (feed molar ratio of 1:1.5).

The PEGylated dendrimers (Fig. 1A) were characterized by 1 H NMR. The spectra for both $\mathrm{G}_{4}$ and $\mathrm{G} 6$ PAMAM-NH2 present the five characteristic signals: $\mathrm{Hg}_{1} \mathrm{~g}^{\prime}(\delta=3.26), \mathrm{He}^{\prime} \quad(\delta=2.82), \mathrm{Hf}(\delta=2.74)$, $\mathrm{He}(\delta=2.63 \mathrm{ppm})$ and $\mathrm{Hd}(\delta=2.43 \mathrm{ppm})$ (Fig. 1B1) [31]. Likewise, the mPEG-COOH spectrum shows its three typical peaks: $\mathrm{Hc}(\delta=4.19 \mathrm{ppm}), \mathrm{Hb}(\delta=3.74 \mathrm{ppm})$ and $\mathrm{Ha}(\delta=3.42 \mathrm{ppm})$ (Fig. 1B2) [32]. The

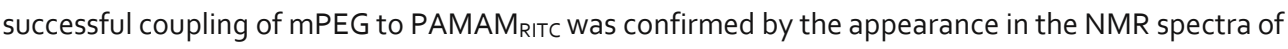
the peaks corresponding to the mPEG protons (Fig. 1B3-B5) and, particularly, by the shift of the signals $\mathrm{He}^{\prime}$ (from PAMAM) and $\mathrm{Hc}$ (from mPEG) to downfield and to upfield respectively, indicating 
the formation of an amide bond between the PAMAM primary amines and the carboxylic acid from PEG.

The number of PEG chains conjugated per dendrimer was quantified by $1 \mathrm{H}$ NMR by integration of the mPEG signals $\left(\mathrm{Hc}, \mathrm{Hb}\right.$ and $\mathrm{Ha}$ ) in relation to the $\mathrm{Hd}$ peak $\left(\delta=2.43 \mathrm{ppm} ; 2481 \mathrm{H}\right.$ in $\mathrm{G}_{4} ; 10161 \mathrm{H}$ in G6) from the dendrimer. The integral values show that there is an increase in the number of $\mathrm{mPEG}$ chains conjugated to the dendrimer with increasing feed molar ratios, and confirm the success of the PEGylation degree according to the feed molar ratios of 4, 8 and 12 mPEG chains (Fig. S1, A-F in supplementary material).

\subsection{PAMAM biocompatibility depends on the generation and concentration}

Despite their growing interest, in vivo application of cationic PAMAM dendrimers has been associated with hemolytic and cytotoxic effects [33,34]. These are mainly dependent on their $\mathrm{G}$ and nature of the surface groups. In this work, the latter are primary amines, which are protonated at physiological $\mathrm{pH}$, contributing to their cationic character and potentiating the interaction with the negatively charged cell membranes. In opposition, PEG chains have been reported to work as effective shielding agents of PAMAM cationic amine termini significantly reducing toxicity [19].

The cytotoxicity of $\mathrm{G}_{4}$ and $\mathrm{G} 6$ PAMAM $\mathrm{RITC}$ was assessed as a function of $\mathrm{G}$, surface functionalization (PEGylation) and concentration to bEnd. 3 cells, a brain endothelial cell line, and primary astrocytes, one of the cell types found in the CNS upon crossing of the BBB. As shown in Fig. 2, G4 PAMAM RITC was not cytotoxic to bEnd. 3 and primary astrocytes at the lowest concentration tested $(0.01 \mathrm{mg} / \mathrm{ml})$,

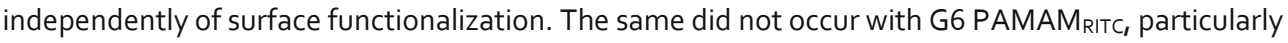
in its non-modified form, which presented significant toxicity even at the lowest tested concentration, confirming the generation-dependent toxicity.

The toxicity of PAMAM increased proportionally with increasing concentration in all formulations tested and for both cell types. At the higher concentrations of 0.1 and $1 \mathrm{mg} / \mathrm{ml}$, the shielding effect of the PEG chains resulted in a significant reduction of toxicity with the functionalized ${ }_{4}$ PAMAM RITC $_{\text {P }}$ at $0.1 \mathrm{mg} / \mathrm{ml}$ showing just a marginal effect on the viability of bEnd.3 cells and no effect towards primary astrocytes. The shielding effect seems to peak with the modification with $8 \mathrm{mPEG}$ chains and no further improvement is observed with 12 chains.

In summary, G6 PAMAM RITC was toxic to both cell types even at the lowest concentration tested. Showing significantly less toxicity, $G_{4}$ PAMAM emerges as a more attractive option for an in vivo drug delivery application, especially when conjugated with $\mathrm{MPEG}$, which provides a shielding effect to the toxicity of the PAMAM amine-termini even at high concentrations. G4 PAMAM RITC-8mPEG showed the most promising results causing no significant decrease on the viability of both bEnd.3 and rat primary astrocytes at concentrations up to $0.1 \mathrm{mg} / \mathrm{ml}$, and were predominantly used for the following assays of this work.

\subsection{Functionalized G4 PAMAM crosses the in vitro BBB without compromising it}


To understand the effect of PAMAM on the BBB, both in terms of its toxicity and capacity to permeate the barrier, a well-established in vitro model of the BBB [26] was reproduced using a coculture of mouse endothelial bEnd. 3 cells and rat primary astrocytes on collagen-coated $0.4-\mu \mathrm{m}$ pore-size transwell ${ }^{\circledR}$ membranes.

The use of bEnd. 3 cells to mimic the endothelial lining of the BBB offers some advantages over the use of primary brain endothelial cells, such as i) the ability to maintain BBB-specific properties over passages; ii) easy maintenance and low cost; and iii) the formation of functional barriers in vitro. Furthermore, their ability to express TJ proteins and efflux transporters justify altogether their wide use in specialised in vitro models of the BBB $[35,36]$. It has also been discussed that astrocytes, when in co-culture with endothelial cells, prevent the latter from losing their phenotype through organspecific signals, thus strengthening the BBB integrity $[2,37,38]$.

The co-culture of bEnd. 3 and rat primary astrocytes showed high membrane integrity with TEER values up to $79.7 \pm 11.9 \Omega$.cm2, which was in accordance with previously reported data $[26,39]$. Regarding the permeability to $\mathrm{NaF}$, the permeability coefficient values were in the order of $5.5 \pm 0.5 \mathrm{~cm} / \mathrm{s}$, which also matched values found in previous work [40].

To further validate the model, the expression of ZO- 1 and Claudin- 5 , two of the predominant proteins found in TJs and reported to occur in bEnd.3 cells and the BBB [[41], [42], [43]], were imaged by fluorescent confocal microscopy (Fig. $\mathrm{S}_{2}$ in supplementary material). The images reveal the characteristic zipper-like localization at the interface between two adjacent cells tightly sealing cellcell junctions [35]. The formation of intercellular junctions [44,45] was confirmed by TEM analysis in the form of electron dense regions between endothelial cells (Fig. S2A). Interestingly, TEM also showed evidence of physical astrocyte-endothelial interaction with astrocytic processes crossing the PET membrane (Fig. $\mathrm{S}_{2} \mathrm{~B}$ and $\mathrm{S}_{2} \mathrm{C}$ ). Although the role of astrocytes in the regulation of the BBB has been widely studied [38], its physical interaction with endothelial cells has seldom been visualised.

The effect of the PEGylated $G_{4}$ PAMAM RITC on the integrity of the BBB was determined by monitoring the TEER of the in vitro BBB model when exposed to PAMAM, over time. Fig. 3 shows that all formulations had a similar effect when compared to the control (untreated cells).

Note that the presence of the dendritic structures actually seemed to induce a tightening of the barrier with the TEER increasing up to $50 \%$ compared to the control. This effect was more evident for the unPEGylated $\mathrm{G}_{4}$ PAMAM dendrimers, which differed significantly from the control at all timepoints from $2 \mathrm{~h}$ onwards. Although this effect was attenuated by functionalization with $\mathrm{MPEG}$, all formulations still produced a significant effect on the barrier at the $3 \mathrm{~h}$ contact time-point, suggesting a more sensitive period of the barrier as is also indicated by the highest decrease in TEER induced by the negative control (SDS).

Interestingly, it was not the first-time that incubation with nanomaterials induced an increase in the TEER of an in vitro BBB model. In the work of Garcia-Garcia et al. [46] this effect was also observed but did not reach statistical significance. Also here, PEGylation attenuated the effect. Other studies show that incubation with PAMAM, at concentrations in the same range of the one tested here, did not significantly affect the barrier permeability, although the TEER was followed just up to $1 \mathrm{~h}[47,48]$. 
Overall, the data indicated that the PEGylated PAMAM did not affect the integrity of the in vitro BBB at the concentration tested $(0.01 \mathrm{mg} / \mathrm{ml})$. Therefore, PEGylated PAMAM should not compromise a healthy BBB. This suggests the potential use of PAMAM to cross a leaky BBB without affecting the integrity of the barrier at other healthy sites.

To study the permeation of the PAMAM conjugates through the in vitro BBB model, the co-cultures were incubated with PAMAM RITC and imaged by confocal laser scanning microscopy after 4 or $24 \mathrm{~h}$ of contact (Fig. 4). For every condition, PAMAMRITC was abundant in the cytoplasm of bEnd. 3 cells. The orthogonal views presented in Fig. 4 provide a 3 -dimensional perspective at both the 4 and $24 \mathrm{~h}$ timepoints. PEGylated PAMAMRITC dendrimers appear to be crossing the endothelial cells to the brain side as they were often found below the bEnd.3 monolayer (white arrows). In contrast, unPEGylated $\mathrm{G}_{4}$ PAMAM RITC dendrimers appear to remain associated with the endothelial cells even after $24 \mathrm{~h}$. This is likely due to the cationic surface charge of PAMAM, which is not shielded by PEG, providing a stronger interaction with the lipidic negatively-charged cell membrane $[25,49,50]$. The increased amount of PEGylated PAMAM in the basolateral side is important as PAMAM is intended to freely pass through a leaky BBB upon injury rather than remaining bound to the endothelium. We hypothesise that the dendrimers cross the BBB by both adsorptive transcytosis as well as by paracellular transport, though this last mechanism might be less significant due to the tight barrier established. This is in line to what was stated by Komarova and Malik where interdependence between both pathways results in the maintenance of tissue fluid homeostasis [51] and to a report from Moscariello and colleagues, where a PAMAM dendrimer bioconjugate was shown to cross an in vitro BBB by transcytosis [52]. It is known that adsorption of nanoparticles to the endothelial cell layer creates a concentration gradient that enhances their transport, important for drug delivery [53]. In our case, the use of positively charged dendrimer aids in the interaction with the negatively charged cell membrane. PEGylation is expected to modulate this interaction by partially masking positive charges, enhancing the intra- and inter-cellular crossing at the BBB. Other reports have shown a clathrin-mediated endocytosis of PAMAM [54] as well as the BBB crossing of PAMAM by passive diffusion through the tight junctions, where PAMAM was functionalized with hydroxyl groups (mixed surface dendrimers) to reduce the positive charge [55]. These authors concluded that such dendrimers can be used to carry drugs that otherwise would not cross the blood-brain barrier.

The association of PAMAM ${ }_{\text {RITC }}$ dendrimers with bEnd. 3 cells was evaluated by flow cytometry after $4 \mathrm{~h}$ contact. There was a significant increase of RITC-positive cells for all PAMAMRITC conditions when compared to free RITC (Fig. S3). This suggests that the cationic structure of PAMAM is potentiating the interaction with the cell membrane, either by binding or internalization, leading to a more extensive association of RITC with the cells. Interestingly, this effect was mitigated with increasing mPEG functionalization. This corroborates the shielding effect offered by PEG by the reduction of available positive charges and by imposing steric hindrance, which limits interaction with the cells [56]. Both effects should promote the crossing of PAMAM through the BBB.

The balance between the results obtained for cell viability, BBB integrity, BBB crossing and cell internalization, for the different PEGylated PAMAM indicate that 8 and $12 \mathrm{mPEG}$ are equivalent but better than 4 mPEG. Therefore, we chose PAMAM 8-mPEG over $12 \mathrm{mPEG}$, as there is no improvement in adding extra PEG chains.

\subsection{G4 PAMAM RITC -8 mPEG dendrimers are hemocompatible}


Based on the data presented above, we chose $\mathrm{G}_{4}$ PAMAMRITC-8mPEG to further explore its application in a stroke scenario. As we aimed for i.v. administration of the functionalized dendrimers, the hemocompatibility of the $\mathrm{G}_{4}$ PAMAMRITC-8MPEG dendrimers was tested by both a hemolysis and a clotting assay, to assure a safe i.v. systemic delivery. The results were compared with the parent unPEGylated dendrimer (G4 PAMAM). As depicted in Fig. 5A, there was a significant difference when comparing the unPEGylated and PEGylated dendrimers regarding hemolysis. Without PEGylation, a low but significant percentage of hemolysis (2.5\%) could be observed, although only after $24 \mathrm{~h}$

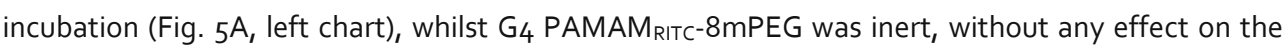
percentage of red blood cell lysis in the 3 tested periods (Fig. $5 \mathrm{~A}$, right chart). This result assures that upon an i.v. administration of $\mathrm{G}_{4}$ PAMAM RITC $-8 \mathrm{mPEG}$ dendrimer one can expect no adverse effects. This is in accordance with the consensual benefits of PEGylation that are found in the open literature [[57], [58], [59]]. The clotting assay using recalcified plasma further expanded on the interesting properties for the proposed dendritic structures, as $\mathrm{G}_{4}$ PAMAM RITC-8mPEG was found to delay the blood clotting time when compared to the reference control without dendrimer (Fig. ${ }_{5} \mathrm{~B}$, right chart). Accordingly, increasing the concentration of dendrimer increased the time needed for clotting, with the highest concentration even preventing clotting until the end of the assay. This anti-coagulation effect observed for our functionalized dendrimers is in accordance with a previous report using $\mathrm{G}_{3}$ PAMAM bound to polyphosphates. This complexation should decrease the positive charges (similar to PEGylation) with benefits for PAMAM hemocompatibilityv [6o]. In contrast, the unPEGylated PAMAM did not interfere with the clotting time i.e. the clotting occurred at the same time as the reference control, without dendrimer, and after the time for the positive control with glass, which accelerates clotting (Fig. 5B, left). There is however a report showing an adverse effect in clotting of cationic PAMAM [61]. However, this was performed with G7 PAMAM, which significantly increases the size and charge of the dendrimer, as previously discussed. Therefore, the clot-like behaviour in that case can be explained by the densely charged cationic dendrimer surface interacting with the negatively charged fibrinogen domains.

\subsection{G4 PAMAM RITC-8 mPEG dendrimers do not compromise the ischemic BBB}

Before administering PAMAM in an in vivo model of ischemic stroke, we performed a biocompatibility assay using the cells composing the BBB (bEnd. 3 and primary astrocytes), faced with $O G D$ as a well established in vitro model to simulate the in vivo scenario after ischemia [62]. After $O G D$, there was a significant alteration in TEER and barrier permeability, indicating that OGD can disturb the in vitro BBB (Fig. $6 \mathrm{~B}$ and $\mathrm{C}$ ). By adding $\mathrm{G}_{4}$ PAMAM ${ }_{\mathrm{RIT}} \mathrm{C}-8 \mathrm{mPEG}$ dendrimers to either bEnd. 3 or primary astrocytes no significant decrease in cell viability was observed (Fig. 6A), indicating that in conditions of brain ischemia induced by OGD, PAMAM dendrimers would not further damage this brain barrier. Additionally, the exposure of $\mathrm{G}_{4}$ PAMAM RITC $-8 \mathrm{mPEG}$ did not affect the barrier integrity or permeability, as no significant changes were observed on TEER and permeability to fluorescein values after $\mathrm{G}_{4}$ PAMAM RITC- $8 \mathrm{MPEG}$ addition (Fig. $6 \mathrm{~B}$ and $\mathrm{C}$ ). Therefore, the $\mathrm{G}_{4}$ PAMAMRITC-8mPEG did not perturb the barrier nor induced further damage on the NVU cells at $0.01 \mathrm{mg} / \mathrm{ml}$, indicating that their use is safe at this concentration. Additionally, the crossing of PAMAM was studied in conditions of OGD and compared with the undisturbed BBB (Fig. 6D and E). A higher amount of PAMAM was found in the basolateral side of the barrier after $4 \mathrm{~h}$ of hypoxia (Fig. $6 D$ ). In accordance, orthogonal view projections reveal a higher amount of PAMAM crossing the membrane insert, between the endothelial cells and the astrocytes (Fig. 6E). A closer inspection of the astrocytes shows a higher intracellular presence of PAMAM when OGD was induced. It has been

INSTITUTO DE INVESTİGAÇÃO E INOVAÇÃO EM SAÚDE UNIVERSIDADE DO PORTO

Rua Alfredo Allen, 208 4200-135 Porto Portugal +351220408800 info@i3s.up.pt www.i3s.up.pt 
previously reported that PAMAM dendrimers can cross the BBB $[52,55,63]$. Here, we report an increase in dendrimer traffic through the barrier subjected to hypoxia, that can be explained by the increase of the paracellular transport [64].

Given the aim of PAMAM application, i.e. systemic administration to cross the compromised BBB due to stroke, the optimized PAMAM formulation ( $\mathrm{G}_{4}$ PAMAM $\mathrm{RIT}_{\mathrm{T}}-8 \mathrm{mPEG}$ ) was characterized by DLS regarding size, PDI and zeta potential to assure a size compatibility with the BBB fenestration induced by brain ischemia and a zeta potential appropriate to electrostatically interact with the negatively charged lipidic cell membranes. Our results show that $\mathrm{G}_{4}$ PAMAMRITC-8mPEG has a hydrodynamic size of $24.2 \mathrm{~nm} \pm 16.2 \mathrm{~nm}$, a PDI of $0.54 \pm 0.11$ and a zeta potential of $11.4 \pm 1.69 \mathrm{mV}$ all compatible with the in vivo administration regarding hydrodynamic size, with values below $100 \mathrm{~nm}$ and a low but still positive zeta potential.

\subsection{Functionalized G4 PAMAM cross the compromised BBB and reach the ischemic brain}

Next, the $\mathrm{G}_{4}$ PAMAM RITC $8 \mathrm{mPEG}$ dendrimer or free RITC were administered i.v. in a mice model of stroke induced by PMCAO. Both the dendrimers or the free RITC were administered immediately after surgery. Animals were euthanized $24 \mathrm{~h}$ post injury and fluorescence analysis conducted on selected tissues.

Urine and blood were analysed for the presence of RITC, 1 and $24 \mathrm{~h}$ after administration. At both time points and in both conditions (free and dendrimer bound RITC) fluorescence was detected by spectrofluorimetry at these time points (data not shown). These observations indicate that that both compounds are circulating and available for tissue delivery, including the brain. PAMAM dendrimers have been reported to be excreted via the hepatobiliary pathway and by renal filtration [65]. This last mechanism represents the ideal route for dendrimers removal from the body $[66,67]$. Due to the importance of this issue in the context of future applications, the assessment of the pharmacokinetics of the proposed nanosystem should be further explored in subsequent studies. Additionally, the correlation between stroke and dendrimer excretion should be clarified as well, since brain injury can alter renal function in mice, similar to what has been reported for patients [68].

The amount of $\mathrm{G}_{4}$ PAMAM $\mathrm{RITC}-8 \mathrm{mPEG}$ was inspected in the ischemic brain and compared with free RITC by imaging analysis. As observed in the images and quantification chart (Fig. 7), there was a significant increase in the amount of RITC dendrimer-conjugated present in the ischemic brain in comparison to free RITC, indicating that PAMAM had a successful role as a delivery vector of this small putative drug. This, possibly results from a better transport across the compromised BBB, as we observed in our in vitro data (Fig. 4, Fig. 6). Also, the presence of the PEG is expected to help in the diffusion of the dendrimers through the brain tissue, from the ipsilateral to the contralateral cortex in agreement to what was previously reported by Nance and colleagues [69].

In the choroid plexus of the brain, the difference between the modified $\mathrm{G}_{4}$ PAMAM and control RITC is striking (Fig. $\mathrm{S}_{4}$ in supplementary material) with a much higher presence at this locus in the case of $\mathrm{G}_{4}$ PAMAMRITC-8mPEG. This is an interesting result, further reinforcing the message of a better RITC transport bound with PAMAM than in a free form. Also, because the choroid plexus produces cerebrospinal fluid lining the brain ventricles, this can be another entrance of PAMAM to the brain [70]. Since a systemic administration was performed, and because PAMAM can be filtered in the 
kidneys, this organ was also inspected (Fig. $\mathrm{S}_{4}$ ). Again, there was a higher $\mathrm{G}_{4}$ PAMAMRITC-8mPEG when compared to free RITC control in accordance with the brain results.

\section{Conclusions}

Successful PEGylation of cationic PAMAM dendrimers effectively increased PAMAM biocompatibility towards bEnd.3 cells and rat primary astrocytes. This effect was further confirmed by incubation of the PEGylated $\mathrm{G}_{4}$ PAMAM with an in vitro co-culture model of the BBB, in which no negative effect towards the barrier integrity was observed. When assessing the transport of RITC (here acting as a model drug) through the BBB, results suggest permeation through bEnd. 3 cells is facilitated by dendrimer PEGylation, which also reduces the association of PAMAM with bEnd.3. Moreover, envisaging a safe systemic intravenous administration, no hemolysis was observed when PEGylated G4 PAMAM was in contact with red blood cells, contrary to unmodified dendrimer. Interestingly, there was a delay in the coagulation time due to the presence of PEGylated G4 PAMAM indicating an added function for this dendrimer. In conditions of hypoxia induced by OGD, the PAMAM dendrimers did not affect the in vitro barrier integrity, indicating a safe crossing of a compromised BBB due to ischemia.

Additionally, PEGylated G4 PAMAM dendrimers were administered in a mice model of permanent ischemic stroke with success. The dendrimers were able to reach the brain, crossing the compromised BBB. Moreover, PEGylated G4 PAMAM dendrimers were detected in neurons, indicating that this delivery vector can reach these cells in the ischemic brain. Overall, our results indicate that PEGylated, amine terminated PAMAM with low generation $\left(\mathrm{G}_{4}\right)$ can be used as an effective delivery vector to the brain with therapeutic purposes in stroke.

In the future, including a targeting moiety with neuronal specificity in these nanostructures should increase the amount of the cargo reaching the ischemic neurons. Such delivery strategy is expected to increase the bioavailability of a therapeutic molecule in neurons, enhancing its effect after stroke. 


\section{Declaration of interest}

The authors declare that there are no known conflicts of interest associated with this publication and there has been no significant financial support for this work that could have influenced its outcome.

\section{Acknowledgements}

The authors acknowledge the financial support of the Fundo para a Investigação em Saúde (INFARMED, project reference FIS-2015-01_CCV_20150630-88), as well as the FEDER funds (NORTE01-0145-FEDER-000008) through the Programa Operacional Competitividade e Internacionalização - COMPETE 2020 and the Portuguese funds through FCT - Fundação para a Ciência e a Tecnologia in the frame of the projects (PTDC/CTM-NAN/112428/2009 and PTDC/CTM-NAN/3547/2014).

Acknowledgements are also due to FCT by the grant PEst-OE/OUI/Ulo674/2013 (COM, Portuguese government). Funding through the project Centro de Química da Madeira - COM+ (M1420-01-0145FEDER-000005, ARDITI) by Madeira Regional Operational Programme (Madeira 1420) is also acknowledged.

S.D. Santos acknowledges the support by FCT for the post-doctoral fellowship (SFRH/BPD/109297/2015).

V. Leiro acknowledges the support by the project NORTE-01-0145-FEDER-000012, financed by Norte Portugal Regional Operational Programme (NORTE 2020), under the PORTUGAL 2020 Partnership Agreement, through the European Regional Development Fund (ERDF).

The authors would also like to acknowledge Frederico Silva (Biochemical and Biophysical Technologies - b2Tech) Rui Fernandes (Histology and Electron Microscopy - HEMS), Sofia Lamas (i3S Animal Facility), Paula Magalhães (Cell Culture and Genotyping - CCGen) and Maria Lazaro (Bioimaging) for the support at i3S Scientific Platforms. The authors acknowledge Centro de Materiais da Universidade do Porto (CEMUP) for NMR analysis. 


\section{REFERENCES}

[1] H.L. Wong, X.Y. Wu, R. Bendayan, Nanotechnological advances for the delivery of CNS therapeutics, Adv. Drug Deliv. Rev. 64 (2012) 686-700.

[2] F.L. Cardoso, D. Brites, M.A. Brito, Looking at the blood-brain barrier: molecular anatomy and possible investigation approaches, Brain Res. Rev. 64 (2010) 328-363.

[3] Y. Shi, L. Zhang, H. Pu, L. Mao, X. Hu, X. Jiang, N. Xu, R.A. Stetler, F. Zhang, X. Liu, R.K. Leak, R.F. Keep, X. Ji, J. Chen, Rapid endothelial cytoskeletal reorganization enables early blood-brain barrier disruption and long-term ischaemic reperfusion brain injury, Nat. Commun. 7 (2016) 10523.

[4] G.A. Donnan, S.M. Davis, M.W. Parsons, H. Ma, H.M. Dewey, D.W. Howells, How to make better use of thrombolytic therapy in acute ischemic stroke, Nat. Rev. Neurol. 7 (2011) 400-409.

[5] A. Schmidt, J. Minnerup, C. Kleinschnitz, Emerging neuroprotective drugs for the treatment of acute ischaemic stroke, Expert Opin Emerg Drugs 18 (2013) 109-120.

[6] V. Leiro, S.D. Santos, C.D.F. Lopes, A.P. Pego, Dendrimers as powerful Building blocks in Central Nervous System Disease: headed for successful nanomedicine, Adv. Funct. Mater. 28 (2017).

[7] J.K. Saucier-Sawyer, Y. Deng, Y.E. Seo, C.J. Cheng, J.W. Zhang, E. Quijano, W.M. Saltzman, Systemic delivery of blood-brain barrier-targeted polymeric nanoparticles enhances delivery to brain tissue, J. Drug Target. 23 (2015) 736-749.

[8] O.C. Farokhzad, R. Langer, Impact of nanotechnology on drug delivery, ACS Nano 3 (2009) 16-20.

[9] V. Leiro V, P.M.D Moreno, A.P. Spencer, M. Fernandez-Villamarin, R. Riguera, E. Fernandez-Megia, A.P. Pego, Biodegradable PEG-dendritic block copolymers: synthesis and biofunctionality assessment as vectors of siRNA, J. Mater. Chem. B 5 (2017).

[10] V. Leiro, S.D. Santos, A.P. Pego, Delivering siRNA with Dendrimers: in vivo Applications, Curr. Gene Ther. 17 (2017) 105-119.

[11] V. Leiro, J.P. Garcia, H. Tomas, A.P. Pego, The present and the future of degradable dendrimers and derivatives in theranostics, Bioconjug. Chem. 26 (2015) 1182-1197.

[12] D. Zhou, L. Cutlar, Y. Gao, W. Wang, J. O'Keeffe-Ahern, S. McMahon, B. Duarte, F. Larcher, B.J. Rodriguez, U. Greiser, W. Wang, The transition from linear to highly branched poly(beta-amino ester)s: Branching matters for gene delivery, Sci. Adv. 2 (2016) e1600102.

[13] Y. D. Zhou, J. Gao, S. O'Keeffe Ahern, Q.Xu A X., U. Huang, W.Wang. Greiser, Development of branched Poly(5-Amino-1-pentanol-co-1,4-butanediol Diacrylate) with high gene transfection potency across diverse cell types, ACS Appl. Mater. Interfaces 8 (2016) 34218-34226.

[14] D. Zhou, L. Pierucci, Y. Gao, J. O'Keeffe Ahern, X. Huang, A. Sigen, W. Wang, Thermo- and pH-Responsive, coacervate-forming hyperbranched Poly(beta-amino ester)s for selective cell binding, ACS Appl. Mater. Interfaces 9 (2017) 5793-5802.

[15] D.A. Tomalia, H. Baker, J. Dewald, M. Hall, G. Kallos, S. Martin, J. Roeck, J. Ryder, P. Smith, A new class of polymers - starburst-dendritic macromolecules, Polym. J. 17 (1985) 117-132.

[16] R. Duncan, L. Izzo, Dendrimer biocompatibility and toxicity, Adv. Drug Deliv. Rev. 57 (2005) 2215-2237.

[17] L. Albertazzi, L. Gherardini, M. Brondi, S.S. Sato, A. Bifone, T. Pizzorusso, G.M. Ratto, G. Bardi, In vivo distribution and toxicity of PAMAM dendrimers in the central nervous system depend on their surface chemistry, Mol. Pharm. 10 (2013) 249-260. 
[18] P.C. Naha, S.P. Mukherjee, H.J. Byrne, Toxicology of engineered nanoparticles: focus on poly(amidoamine) dendrimers, Int. J. Environ. Res. Public Health 15 (2018).

[19] D. Luong, P. Kesharwani, R. Deshmukh, M.C.I. Mohd Amin, U. Gupta, K. Greish, A.K. lyer, PEGylated PAMAM dendrimers: enhancing efficacy and mitigating toxicity for effective anticancer drug and gene delivery, Acta Biomater. 43 (2016) 14-29.

[20] T.P. Thomas, I. Majoros, A. Kotlyar, D. Mullen, M.M. Holl, J.R. Baker Jr., Cationic poly(amidoamine) dendrimer induces lysosomal apoptotic pathway at therapeutically relevant concentrations, Biomacromolecules 10 (2009) 3207-3214

[21] C.S. Ahuja, M. Fehlings, Concise review: bridging the gap: novel neuroregenerative and neuroprotective strategies in spinal cord injury, Stem Cells Transl. Med. 5(2016) 914-924.

[22] M. Goncalves, D. Maciel, D. Capelo, S. Xiao, W. Sun, X. Shi, J. Rodrigues, H. Tomas, Y. Li, Dendrimer-assisted formation of fluorescent nanogels for drug delivery and intracellular imaging, Biomacromolecules 15 (2014) 492499 .

[23] S. Wen, K. Li, H. Cai, Q. Chen, M. Shen, Y. Huang, C. Peng, W. Hou, M. Zhu, G. Zhang, X. Shi, Multifunctional dendrimer-entrapped gold nanoparticles for dual mode CT/MR imaging applications, Biomaterials 34 (2013) 15701580.

[24] J. Kimura-Kuroda, X. Teng, Y. Komuta, N. Yoshioka, K. Sango, K. Kawamura, G. Raisman, H. Kawano, An in vitro model of the inhibition of axon growth in the lesion scar formed after central nervous system injury, Mol. Cell. Neurosci. 43 (2010) 177-187.

[25] M. Goncalves, R. Castro, J. Rodrigues, H. Tomas, The effect of PAMAM dendrimers on mesenchymal stem cell viability and differentiation, Curr. Med. Chem. 19 (2012) 4969-4975.

[26] J.P. Martins, C.J. Alves, E. Neto, M. Lamghari, Communication from the periphery to the hypothalamus through the blood-brain barrier: An in vitro platform, Int. J. Pharm. 499 (2016) 119-130.

[27] S. Veszelka, M. Pasztoi, A.E. Farkas, I. Krizbai, T.K. Ngo, M. Niwa, C.S. Abraham, M.A. Deli, Pentosan polysulfate protects brain endothelial cells against bacterial lipopolysaccharide-induced damages, Neurochem. Int. 50 (2007) 219-228.

[28] C.G. Pinto, Daniela M.Sousa AM, R.Ferreira Ana, J. AgostinhoMoreira, C.Gonçalves Inês, D. Magalhães Fernão, Smaller particle size and higher oxidation improves biocompatibility of graphene-based materials, Carbon 99 (2016) 318-329.

[29] P. Young, L. Qiu, D. Wang, S. Zhao, J. Gross, G. Feng, Single-neuron labeling with inducible Cre-mediated knockout in transgenic mice, Nat. Neurosci. 11 (2008) 721-728.

[30] C. Karabiyik, R. Fernandes, F.R. Figueiredo, R. Socodato, C. Brakebusch, K.L. Lambertsen, J.B. Relvas, S.D. Santos, Neuronal Rho GTPase Rac1 elimination confers neuroprotection in a mouse model of permanent ischemic stroke, Brain Pathol. (2017).

[31] F. Wang, N. Shao, Y. Cheng, Paramagnetic NMR investigation of dendrimer-based host-guest interactions, PLOS ONE 8 (2013) e64722.

[32] H. He, Y. Li, X.R. Jia, J. Du, X. Ying, W.L. Lu, J.N. Lou, Y. Wei, PEGylated Poly (amidoamine) dendrimer-based dual-targeting carrier for treating brain tumors, Biomaterials 32 (2011) 478-487.

[33] R. Jevprasesphant, J. Penny, R. Jalal, D. Attwood, N.B. McKeown, A. D'Emanuele, The influence of surface modification on the cytotoxicity of PAMAM dendrimers, Int. J. Pharm. 252 (2003) 263-266.

[34] N. Malik, R. Wiwattanapatapee, R. Klopsch, K. Lorenz, H. Frey, J.W. Weener, E.W. Meijer, W. Paulus, R. Duncan, Dendrimers: relationship between structure and biocompatibility in vitro, and preliminary studies on the biodistribution of 125 llabelled polyamidoamine dendrimers in vivo, J. Control. Release 65 (2000) 133-148.

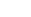


[35] D.M. Wuest, A.M. Wing, K.H. Lee, Membrane configuration optimization for a murine in vitro blood-brain barrier model, J. Neurosci. Methods 212 (2013) 211-221.

[36] R.S. Dhanikula, T. Hammady, P. Hildgen, On the mechanism and dynamics of uptake and permeation of polyether-copolyester dendrimers across an in vitro bloodbrain barrier model, J. Pharm. Sci. 98 (2009) 3748-3760.

[37] N.J. Abbott, Astrocyte-endothelial interactions and blood-brain barrier permeability, J. Anat. 200 (2002) 629638.

[38] N.J. Abbott, L. Ronnback, E. Hansson, Astrocyte-endothelial interactions at the blood-brain barrier, Nat. Rev. Neurosci. 7 (2006) 41-53.

[39] H.C. Helms, N.J. Abbott, M. Burek, R. Cecchelli, P.O. Couraud, M.A. Deli, C. Forster, H.J. Galla, I.A. Romero, E.V. Shusta, M.J. Stebbins, E. Vandenhaute, B. Weksler, B. Brodin, In vitro models of the blood-brain barrier: an overview of commonly used brain endothelial cell culture models and guidelines for their use, J. Cereb. Blood Flow Metab. 36 (2016) 862-89o.

[40] G. Sharma, A. Modgil, T. Zhong, C. Sun, J. Singh, Influence of short-chain cellpenetrating peptides on transport of doxorubicin encapsulating receptor-targeted liposomes across brain endothelial barrier, Pharm. Res. $31(2014) 1194-1209$.

[41] T. Nitta, M. Hata, S. Gotoh, Y. Seo, H. Sasaki, N. Hashimoto, M. Furuse, S. Tsukita, Size-selective loosening of the blood-brain barrier in claudin-5-deficient mice, J. Cell Biol. 161 (2003) 653-66o.

[42] R.C. Brown, A.P. Morris, R.G. O'Neil, Tight junction protein expression and barrier properties of immortalized mouse brain microvessel endothelial cells, Brain Res. 1130 (2007) 17-30.

[43] P.M. Watson, J.C. Paterson, G. Thom, U. Ginman, S. Lundquist, C.I. Webster, Modelling the endothelial blood-CNS barriers: a method for the production of robust in vitro models of the rat blood-brain barrier and bloodspinal cord barrier, BMC Neurosci. 14 (2013) 59.

[44] L. Gonzalez-Mariscal, R. Tapia, D. Chamorro, Crosstalk of tight junction components with signaling pathways, Biochim. Biophys. Acta 1778 (2008) 729-756.

[45] S. Nakagawa, M.A. Deli, H. Kawaguchi, T. Shimizudani, T. Shimono, A. Kittel, K. Tanaka, M. Niwa, A new blood-brain barrier model using primary rat brain endothelial cells, pericytes and astrocytes, Neurochem. Int. 54 (2009) $253-263$.

[46] E. Garcia-Garcia, S. Gil, K. Andrieux, D. Desmaele, V. Nicolas, F. Taran, D. Georgin, J.P. Andreux, F. Roux, P. Couvreur, A relevant in vitro rat model for the evaluation of blood-brain barrier translocation of nanoparticles, Cell. Mol. Life Sci. 62 (2005) 1400-1408.

[47] Y. Liu, R. Huang, L. Han, W. Ke, K. Shao, L. Ye, J. Lou, C. Jiang, Brain-targeting gene delivery and cellular internalization mechanisms for modified rabies virus glycoprotein RVG29 nanoparticles, Biomaterials 30 (2009) 4195-4202.

[48] R. Huang, L. Han, J. Li, F. Ren, W. Ke, C. Jiang, Y. Pei, Neuroprotection in a 6- hydroxydopamine-lesioned Parkinson model using lactoferrin-modified nanoparticles, J. Gene Med. 11 (2009) 754-763.

[49] K.M. Kitchens, M.E. El-Sayed, H. Ghandehari, Transepithelial and endothelial transport of poly (amidoamine) dendrimers, Adv. Drug Deliv. Rev. 57 (2005) 2163-2176.

[50] K. Jain, P. Kesharwani, U. Gupta, N.K. Jain, Dendrimer toxicity: let's meet the challenge, Int. J. Pharm. 394 (2010) 122-142.

[51] Y. Komarova, A.B. Malik, Regulation of endothelial permeability via paracellular and transcellular transport pathways, Annu. Rev. Physiol. 72 (2010) 463-493. 
[52] P. Moscariello, D.Y.W. Ng, M. Jansen, T. Weil, H.J. Luhmann, J. Hedrich, Brain delivery of multifunctional dendrimer protein Bioconjugates, Adv Sci (Weinh) 5 (2018) 1700897.

[53] S.B. Nair, A. Dileep, G.K. Rajanikant, Nanotechnology based diagnostic and therapeutic strategies for neuroscience with special emphasis on ischemic stroke, Curr. Med. Chem. 19 (2012) 744-756.

[54] L. Albertazzi, M. Serresi, A. Albanese, F. Beltram, Dendrimer internalization and intracellular trafficking in living cells, Mol. Pharm. 7 (2010) 680-688.

[55] B. Srinageshwar, S. Peruzzaro, M. Andrews, K. Johnson, A. Hietpas, B. Clark, C. McGuire, E. Petersen, J. Kippe, A. Stewart, O. Lossia, A. Al-Gharaibeh, A. Antcliff, R. Culver, D. Swanson, G. Dunbar, A. Sharma, J. Rossignol, PAMAM dendrimers cross the blood-brain barrier When administered through the carotid artery in C57BL/6J mice, Int. J. Mol. Sci. 18 (2017).

[56] D.M. Sweet, R.B. Kolhatkar, A. Ray, P. Swaan, H. Ghandehari, Transepithelial transport of PEGylated anionic poly(amidoamine) dendrimers: implications for oral drug delivery, J. Control. Release 138 (2009) 78-85.

[57] H.B. Agashe, T. Dutta, M. Garg, N.K. Jain, Investigations on the toxicological profile of functionalized fifthgeneration poly (propylene imine) dendrimer, J. Pharm. Pharmacol. 58 (2006) 1491-1498.

[58] S.J. Guillaudeu, M.E. Fox, Y.M. Haidar, E.E. Dy, F.C. Szoka, J.M. Frechet, PEGylated dendrimers with core functionality for biological applications, Bioconjug. Chem. 19 (2008) 461-469.

[59] M.U. Gurbuz, K. Ozturk, A.S. Erturk, D. Yoyen-Ermis, G. Esendagli, S. Calis, M. Tulu, Cytotoxicity and biodistribution studies on PEGylated EDA and PEG cored PAMAM dendrimers, J. Biomater. Sci. Polym. Ed. 27 (2016) $1645-1658$.

[6o] S. Jain, G.A. Pitoc, E.K. Holl, Y. Zhang, L. Borst, K.W. Leong, J. Lee, B.A. Sullenger, Nucleic acid scavengers inhibit thrombosis without increasing bleeding, Proc. Natl. Acad. Sci. U. S. A. 109 (2012) 12938-12943.

[61] C.F. Jones, R.A. Campbell, A.E. Brooks, S. Assemi, S. Tadjiki, G. Thiagarajan, C. Mulcock, A.S. Weyrich, B.D. Brooks, H. Ghandehari, D.W. Grainger, Cationic PAMAM dendrimers aggressively initiate blood clot formation, ACS Nano 6 (2012) 9900-9910.

[62] T. Koto, K. Takubo, S. Ishida, H. Shinoda, M. Inoue, K. Tsubota, Y. Okada, E. Ikeda, Hypoxia disrupts the barrier function of neural blood vessels through changes in the expression of claudin-5 in endothelial cells, Am. J. Pathol. 170 (2007) 1389-1397.

[63] R. Hemmer, A. Hall, R. Spaulding, B. Rossow, M. Hester, M. Caroway, A. Haskamp, S. Wall, H.A. Bullen, C. Morris, K.L. Haik, Analysis of biotinylated generation 4 poly (amidoamine) (PAMAM) dendrimer distribution in the rat brain and toxicity in a cellular model of the blood-brain barrier, Molecules 18 (2013) 11537-11552.

[64] D. Knowland, A. Arac, K.J. Sekiguchi, M. Hsu, S.E. Lutz, J. Perrino, G.K. Steinberg, B.A. Barres, A. Nimmerjahn, D. Agalliu, Stepwise recruitment of transcellular and paracellular pathways underlies blood-brain barrier breakdown in stroke, Neuron 82 (2014) 603-617.

[65] D.A. Tomalia, L.A. Reyna, S. Svenson, Dendrimers as multi-purpose nanodevices for oncology drug delivery and diagnostic imaging, Biochem. Soc. Trans. 35 (2007) 61-67.

[66] F. Alexis, E. Pridgen, L.K. Molnar, O.C. Farokhzad, Factors affecting the clearance and biodistribution of polymeric nanoparticles, Mol. Pharm. 5 (2008) 505-515.

[67] M. Longmire, P.L. Choyke, H. Kobayashi, Clearance properties of nano-sized particles and molecules as imaging agents: considerations and caveats, Nanomedicine (London) 3 (2008) 703-717.

[68] K. Chwojnicki, E. Krol, L. Wierucki, G. Kozera, P. Sobolewski, W.M. Nyka, T. Zdrojewski, Renal dysfunction in post-stroke patients, PLoS ONE 11 (2016) e0159775. 
[69] E.A. Nance, G.F. Woodworth, K.A. Sailor, T.Y. Shih, Q. Xu, G. Swaminathan, D. Xiang, C. Eberhart, J. Hanes, A dense poly(ethylene glycol) coating improves penetration of large polymeric nanoparticles within brain tissue, Sci. Transl. Med. 4 (2012) 149 ra119.

[70] C.E. Johanson, J.A. Duncan, E.G. Stopa, A. Baird, Enhanced prospects for drug delivery and brain targeting by the choroid plexus-CSF route, Pharm. Res. 22 (2005) 1011-1037. 


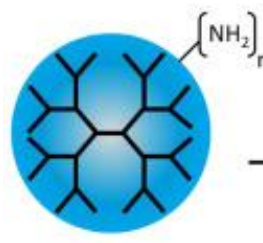

PAMAM-NH

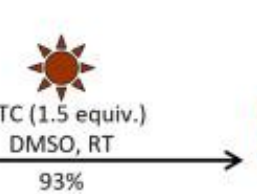

$93 \%$

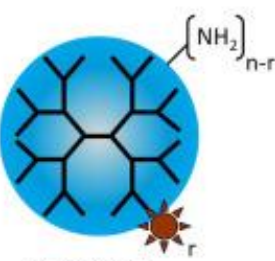

PAMAM- $\mathrm{NH}_{2}$

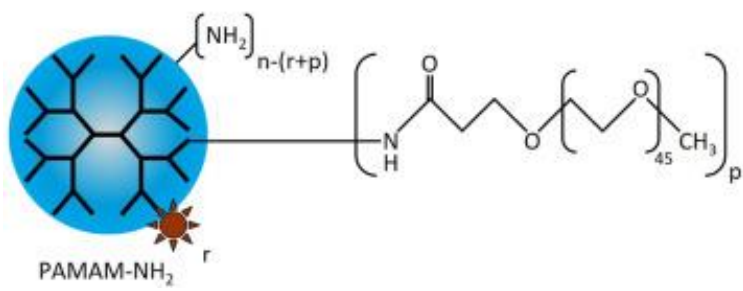

$n=64(\mathrm{G} 4) ; n=256(\mathrm{G} 6)$

$p=4,8,12$

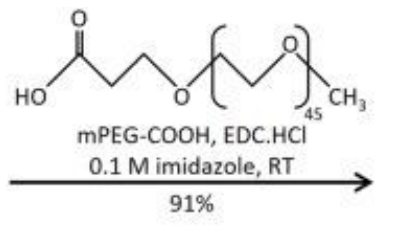

Scheme 1. RITC-labelling and $\mathrm{mPEG}$ conjugation of PAMAM-NH .

Rua Alfredo Allen, 208 4200-135 Porto Portugal $+351220408800$ 
A

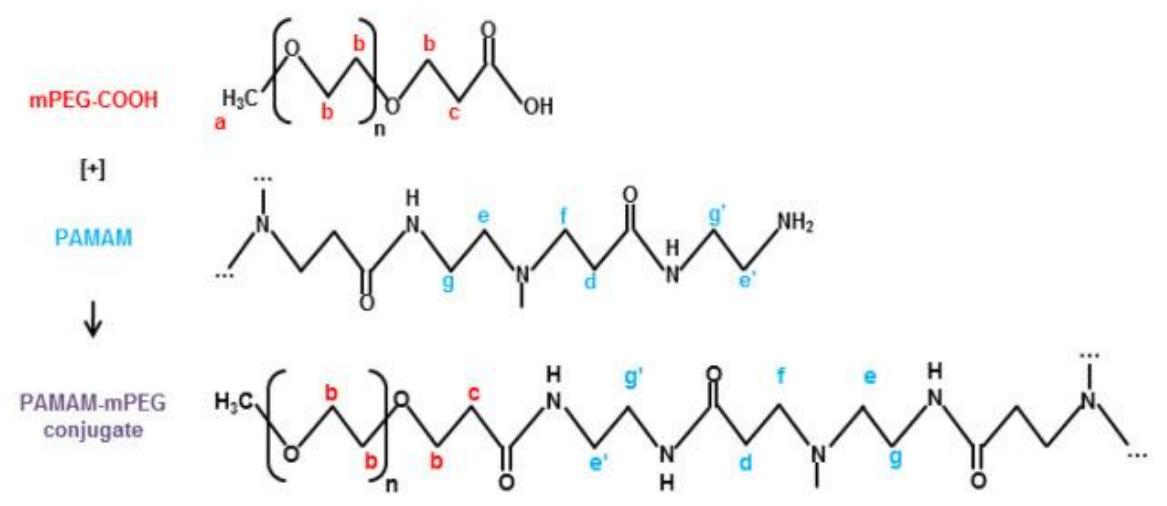

B

G4 PAMAM-NH

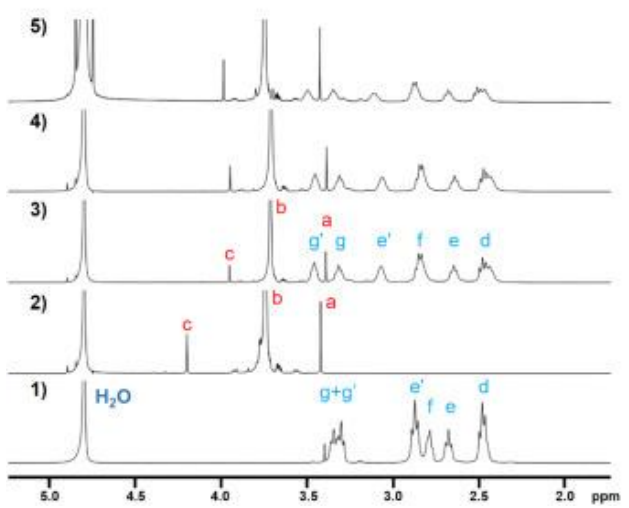

G6 PAMAM-NH

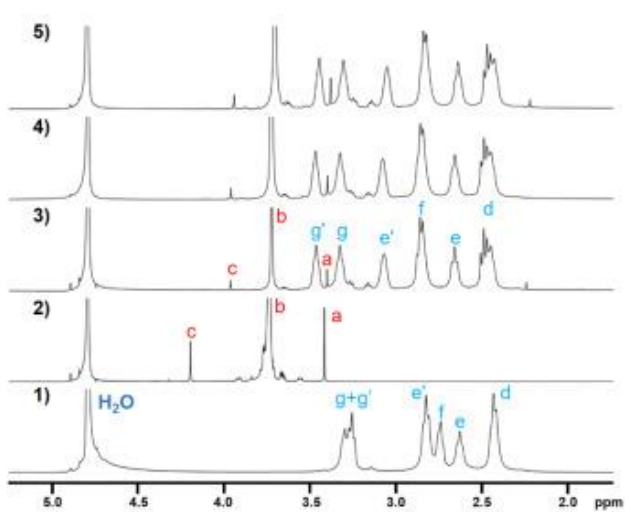

Fig. 1. (A) Functionalization of PAMAM with mPEG-COOH. (B) $1 \mathrm{H}$ NMR spectra (400 $\mathrm{MHz}, \mathrm{D}_{2} \mathrm{O}$ ) of 1 ) $\mathrm{G}_{4} / \mathrm{G} 6$ PAMAM -NH2; 2) mPEG-COOH; 3 ) G4/G6-NH2-RITC-4mPEG; 4) G4/G6-NH2-RITC-8mPEG and 5) G4/G6-NH2RITC-12mPEG.

Rua Alfredo Allen, 208 4200-135 Porto 
A

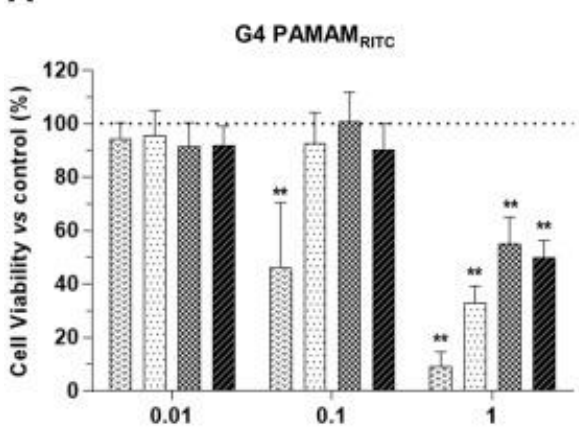

Dendrimer concentration $(\mathrm{mg} / \mathrm{ml})$

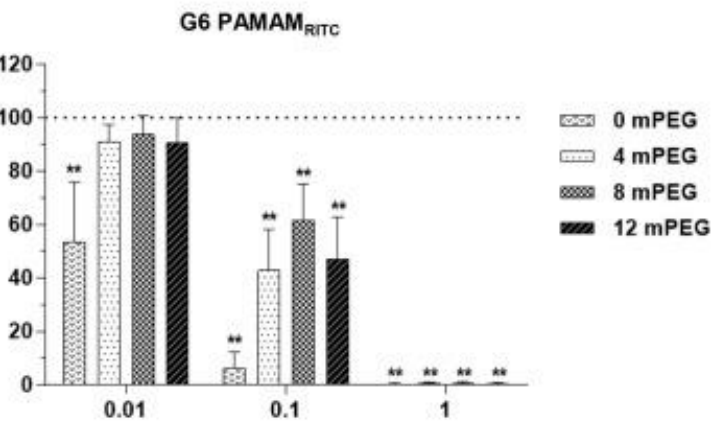

Dendrimer concentration $(\mathrm{mg} / \mathrm{ml})$

\section{B}
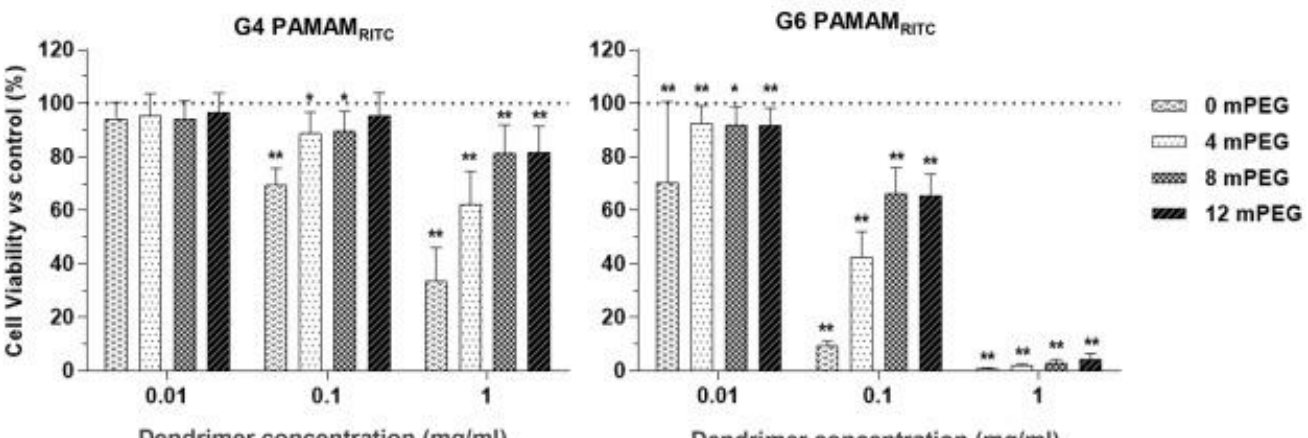

Fig. 2. Effect of PAMAM dendrimers on cellular viability as a function of surface functionalization $(0,4,8$ and 12 $\mathrm{mPEG}$ chains) and concentration (0.01, 0.1 and $1 \mathrm{mg} / \mathrm{ml}$ ) for both $\mathrm{G}_{4}$ PAMAMRITC (left chart) and G6 PAMAMRITC (right chart) (A) bEnd.3 cells metabolic activity $(n=9)$. (B) rat primary astrocytes metabolic activity $(n=6)$. Results are expressed in relation to control (cells without PAMAM). Values represent mean $\pm S D(* p<0.05, * * p<0.01)$. 


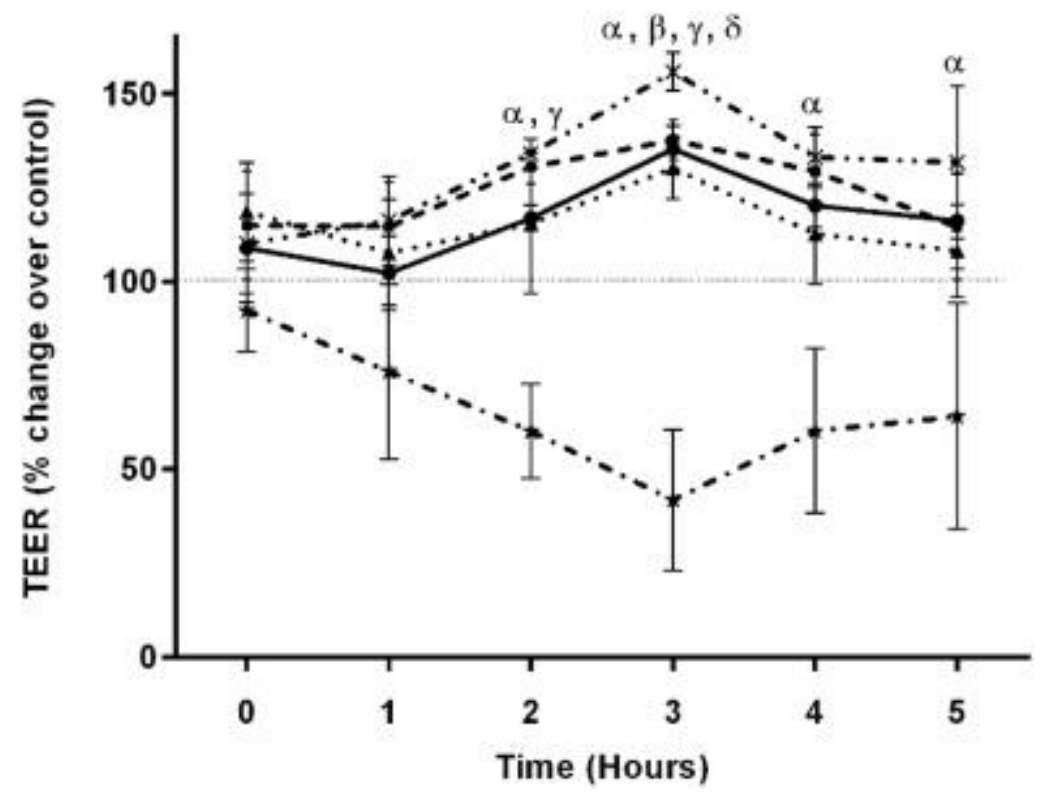

Fig. 3. Effect of PEGylated $G_{4}$ PAMAMRITC on the integrity of an in vitro BBB model. TEER of bEnd.3/astrocytes

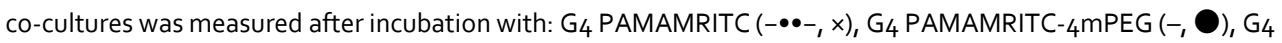
PAMAMRITC-8mPEG $(--, \mathbf{\square})$ and G4 PAMAMRITC-12mPEG $(\bullet, \boldsymbol{\Delta})$ conjugates. Sodium dodecyl sulphate (SDS; $-\bullet-, \star)$ was used as positive control. Values are expressed as mean percentage over baseline control (untreated cells) (Statistical analysis: $\alpha G_{4}$ vs baseline control; $\beta G_{4}$ PAMAMRITC-4mPEG vs baseline control;

$\gamma G_{4}$ PAMAMRITC-8mPEG vs baseline control; $\delta G_{4}$ PAMAMRITC-12-mPEG vs baseline control; $n=3 ; p<.05$ ). 
A
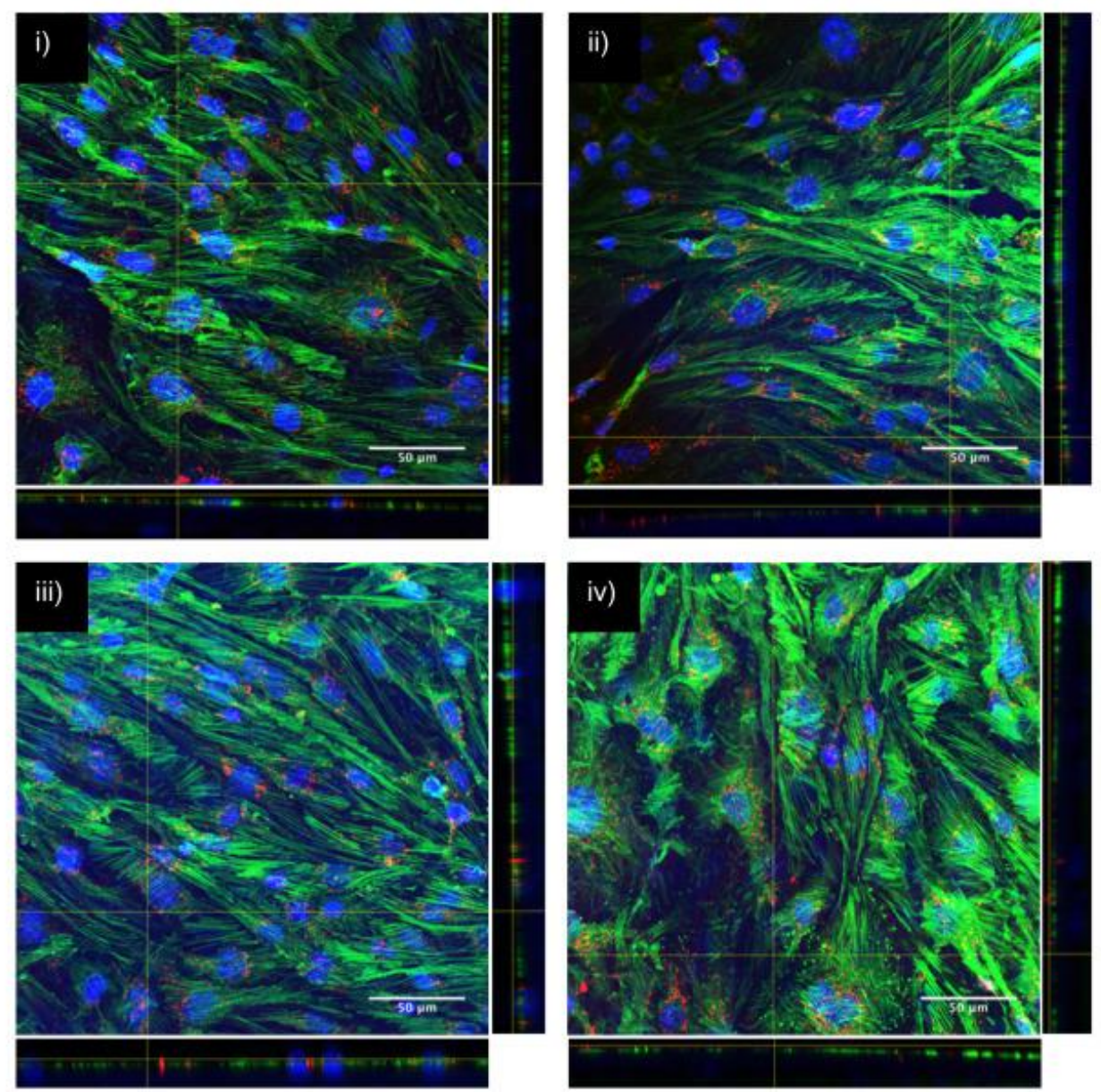

\section{B}
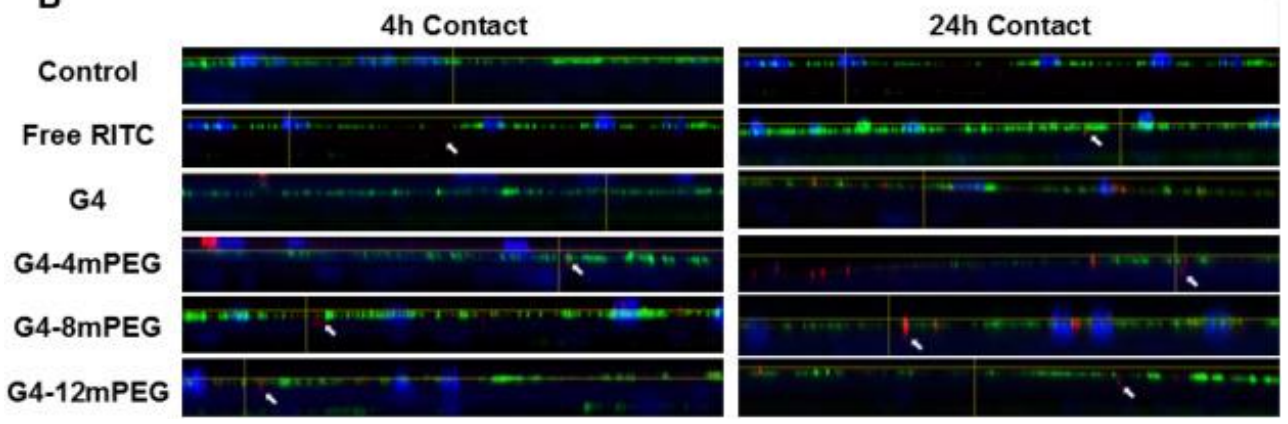

Fig. 4. Fluorescent confocal microscopy images showing bEnd.3/rat primary astrocytes in vitro BBB model in contact with PEGylated G4 PAMAMRITC dendrimers (A) max intensity Z projections and orthogonal views of the in vitro BBB model layers at $24 \mathrm{~h}$, after 4 -hours contact with i) G4 PAMAMRITC, ii) G4 PAMAMRITC-4mPEG, iii) $G_{4}$ PAMAMRITC-8mPEG and iv) G4 PAMAMRITC-12mPEG is shown in red, the cell nuclei are stained with Hoechst (blue) and F-actin was stained with Alexa Fluor ${ }^{\circledR} 488$ phalloidin. (B) Horizontal orthogonal views of the in vitro BBB model at 4 and $24 \mathrm{~h}$ after $4 \mathrm{~h}$ contact with PAMAMRITC conjugates or free RITC. White arrowheads point to RITC 
(free and bound to PAMAM dendrimer) crossing the endothelial barrier towards the brain side. (For interpretation of the references to colour in this figure legend, the reader is referred to the web version of this article.)

A

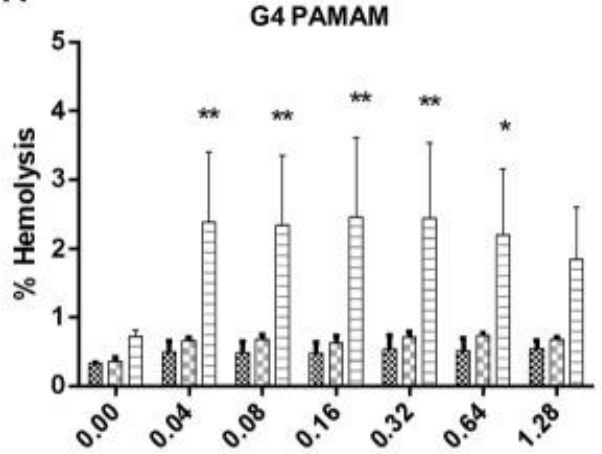

Dendrimer concentration $(\mathrm{mg} / \mathrm{ml})$

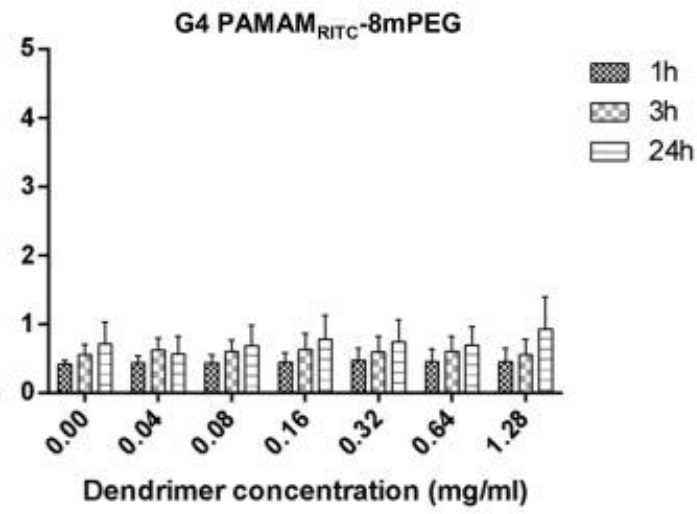

B
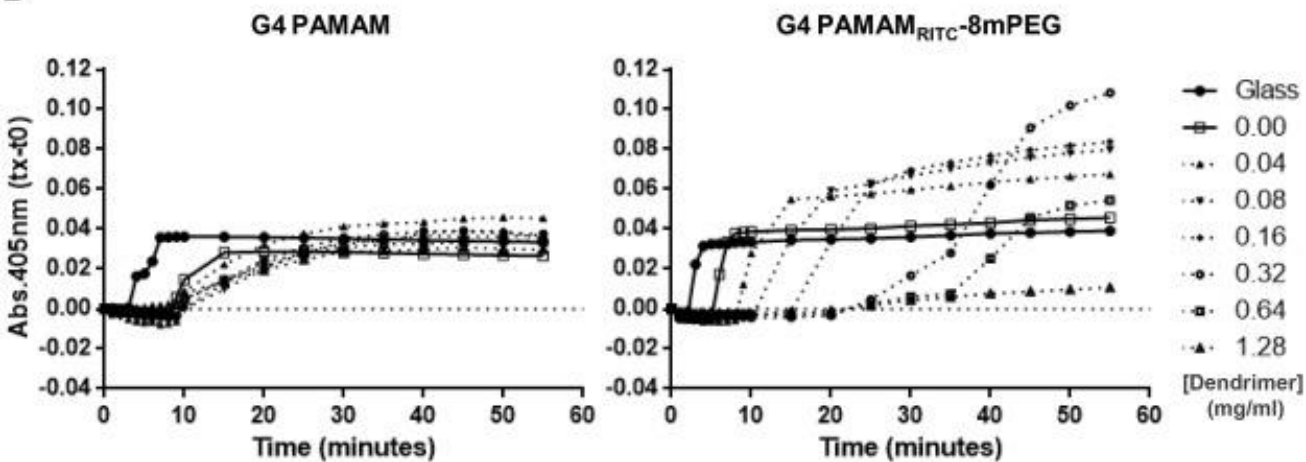

Fig. 5. Hemocompatibility of $G_{4}$ PAMAM dendrimer. (A) Percentage of red blood cells lysis incubated with different concentrations of $\mathrm{G}_{4}$ PAMAM (let chart) or $\mathrm{G}_{4}$ PAMAMRITC-8MPEG (right chart), during different periods of time. Results were calculated using $100 \%$ hemolysis obtained with $1 \%(\mathrm{v} / \mathrm{v})$ Triton $* * \mathrm{p}<.01, * \mathrm{p}<.05$ in comparison to red blood cell lysis control without PAMAM incubation (0.00 mg/ml). (B) Clotting assay performed after incubating recalcified plasma with different concentrations of $\mathrm{G}_{4}$ PAMAM (left chart, dashed lines) or $\mathrm{G}_{4}$ PAMAMRITC-8mPEG (right chart, dashed lines) for $1 \mathrm{~h}$. Glass (solid line;, 0 ) was used as a positive control). Clotting time of control without dendrimer (solid line;,$\square$ ) was analysed as a reference value $\ln A$ and in $B$, data were collected in triplicates from 2 independent assays and are expressed as mean \pm SD. 
A

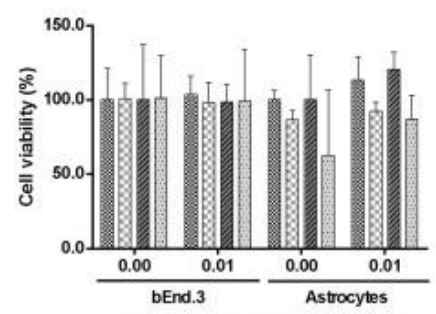

Dendrimer concentration (mg/ml)

C

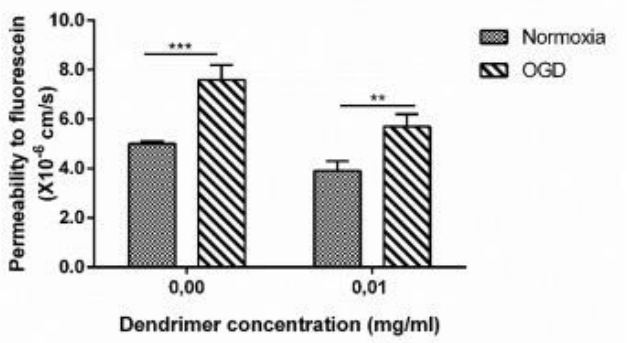

$E$

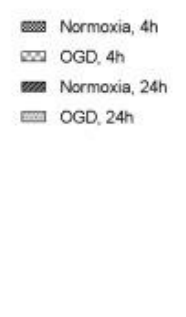

B
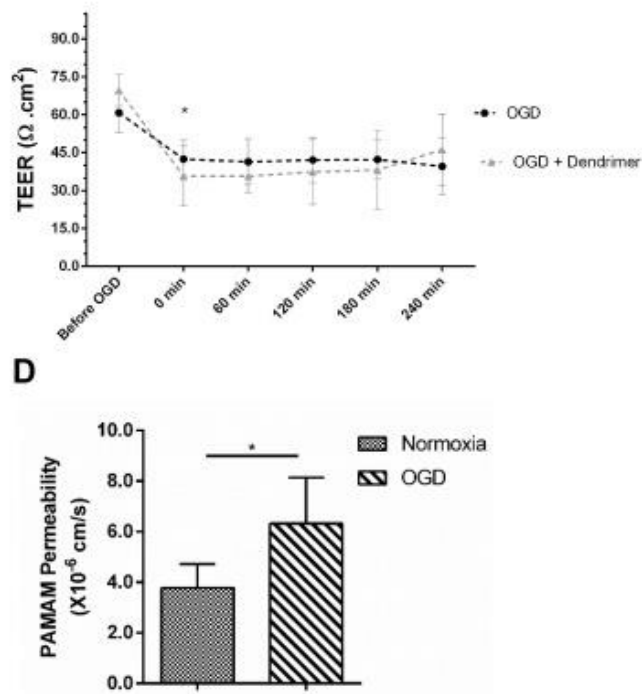
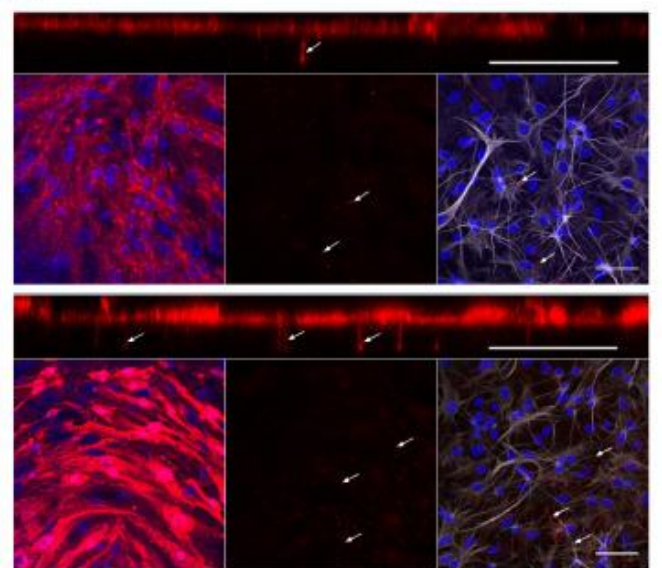

Fig. 6. G4 PAMAMRITC-8mPEG studies with ischemic bEnd.3 cells and astrocytes. (A) The cellular metabolic activity of bEnd. 3 and astrocytes subject to OGD was measured after 4 or $24 \mathrm{~h}$ of contact with $0.01 \mathrm{mg} / \mathrm{ml}$ PAMAM. The presented values were calculated in relation the corresponding control cells without PAMAM and without OGD. (B) in vitro BBB integrity measured by TEER, before and after OGD and for a period of $240 \mathrm{~min}$ after PAMAM addition. (C) In vitro BBB permeability after $1 \mathrm{~h}$ PAMAM incubation in conditions of OGD, measured by fluorescein addition by fluorescence spectroscopy, $(D)$ in vitro BBB permeability to PAMAM dendrimers after OGD, measured by fluorescence spectroscopy. (E) Orthogonal representation of the BBB subject to OGD and after $1 \mathrm{~h}$ contact with PAMAM (red). The different layers of the in vitro BBB: endothelial cells; insert membrane and astrocytes are shown below the orthogonal projections. Nuclei are stained with Hoechst (blue) and astrocytes with GFAP (grey). The values represent mean \pm SD (data from three in dependent experiments). $* * * p<.001, * * p<.01$, $* p<.05$. Scale bar: $50 \mu \mathrm{m}$. (For interpretation of the references to colour in this figure legend, the reader is referred to the web version of this article.) 


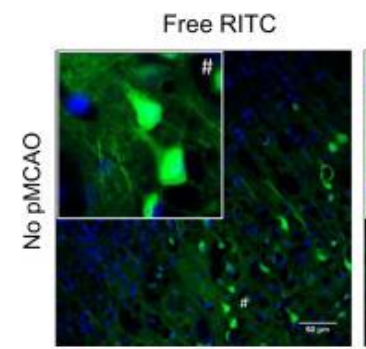

G4 PAMAM RITC $^{-8}$ mPEG
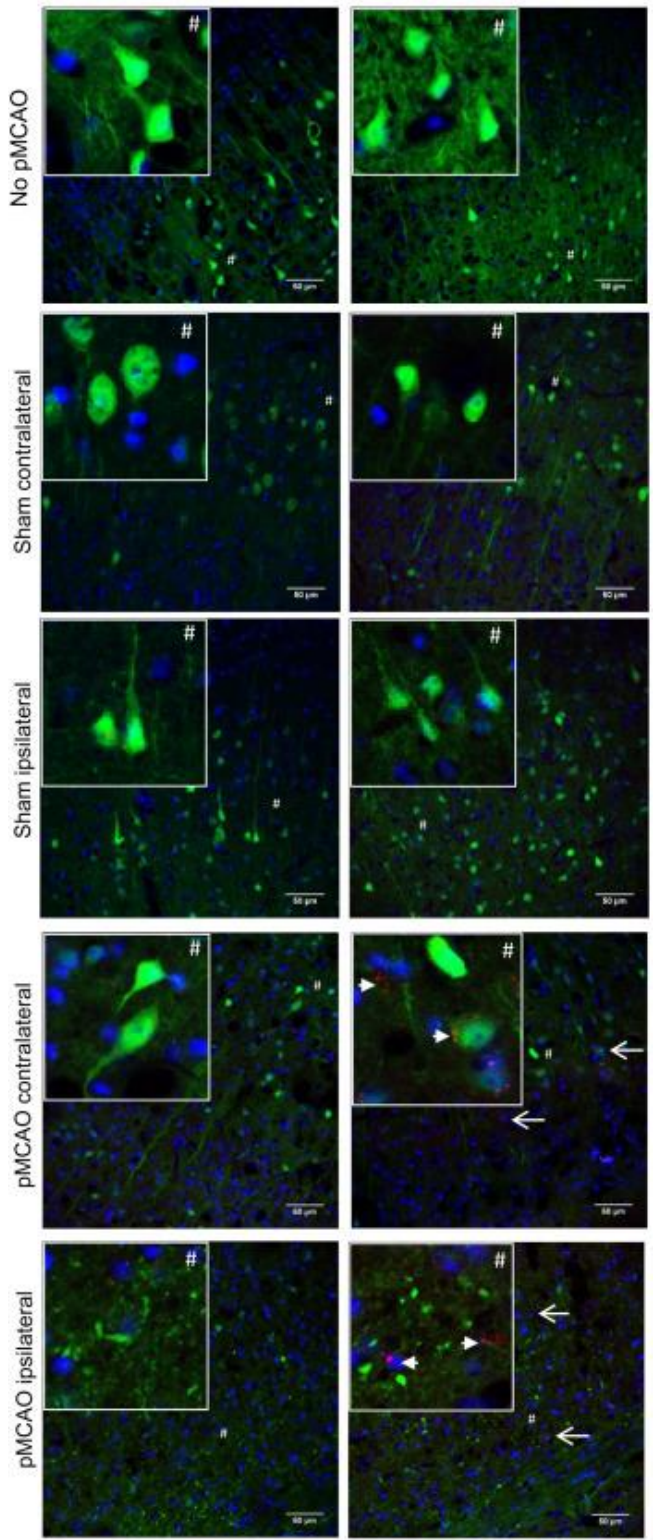

Brain Cortex

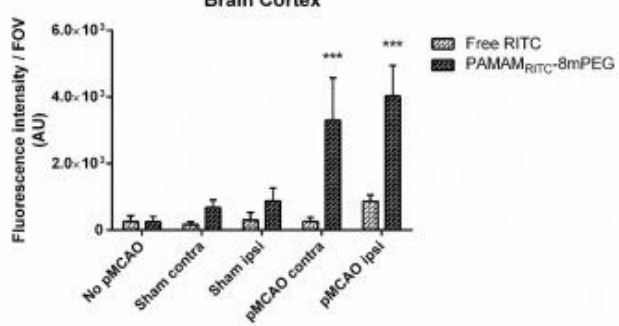

Fig. 7. RITC brain quantification. G4 PAMAMRITC-8MPEG (red) and control free RITC (red) were inspected and quantified in the brain: control no pMCAO, control sham and PMCAO, $24 \mathrm{~h}$ after i.v. administration, by image analysis. The ipsilateral cortex (with lesion) and the contralateral cortex were selected as the area for analysis. Neurons are labelled in green and nucleus in blue. Arrows point to the dendrimer presence. \# denote the zoom in

INSTITUTO

DE INVESTİGAÇÃO

E INOVAÇÃO

EM SAÚDE

UNIVERSIDADE

DO PORTO

Rua Alfredo Allen, 208 4200-135 Porto

Portugal

$+351220408800$

info@i3s.up.pt

www.i3s.up.pt 
area. Fluorescence quantification is presented in the chart. FOV: field of view. No pMCAO: $n=3$, sham $n=3$ and pMCAO: $\mathrm{n}=4$ for each administration. $* * * \mathrm{p}<.001$. Values are expressed as mean $\pm \mathrm{SD}$. (For interpretation of the references to colour in this figure legend, the reader is referred to the web version of this article.)

Table 1. Quantification of RITC (UV-vis spectroscopy) and mPEG chains (1 H NMR spectroscopy) in the functionalized $\mathrm{G}_{4}$ and $\mathrm{G} 6$ PAMAM-NH 2 dendrimers.

RITC modification Theoretic MPEG chains mPEG modification Theoretic Mw (kDa)

G4 PAMAM - $\mathrm{NH}_{2} 1.346$

G6 PAMAM - $\mathrm{NH}_{2} 1.436$ 


\section{Supplementary material}

\section{Figure S1}

A

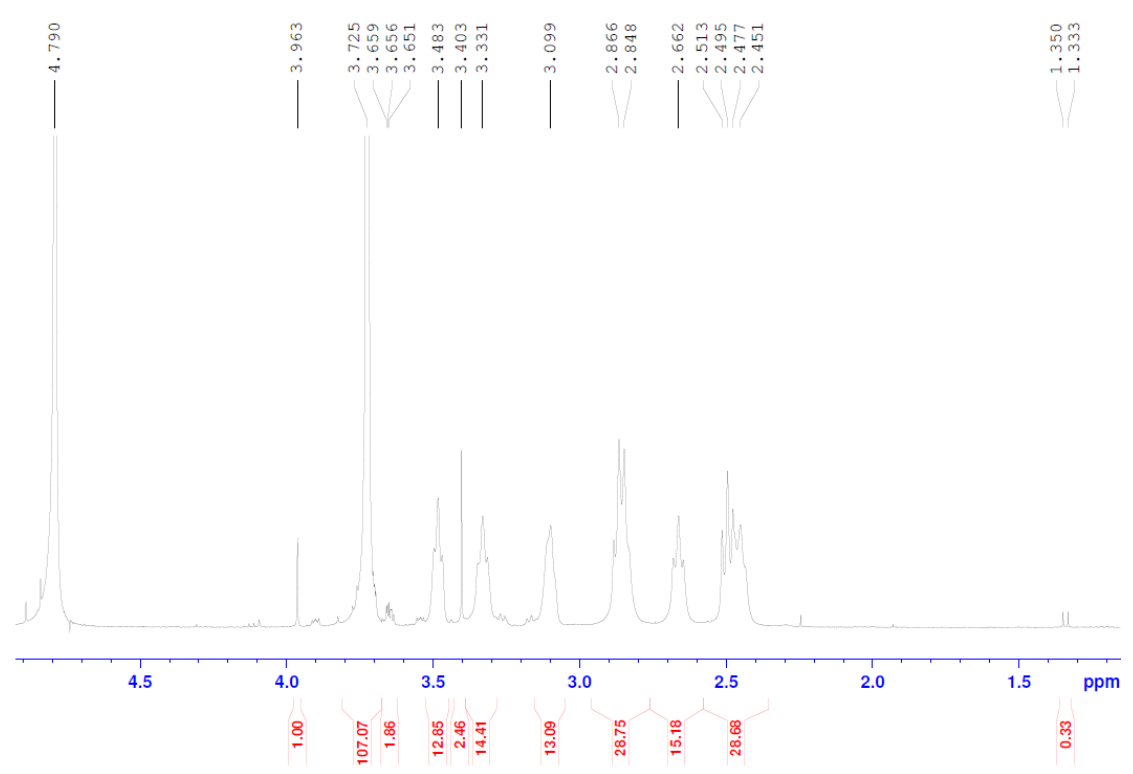

$\mathbf{B}$

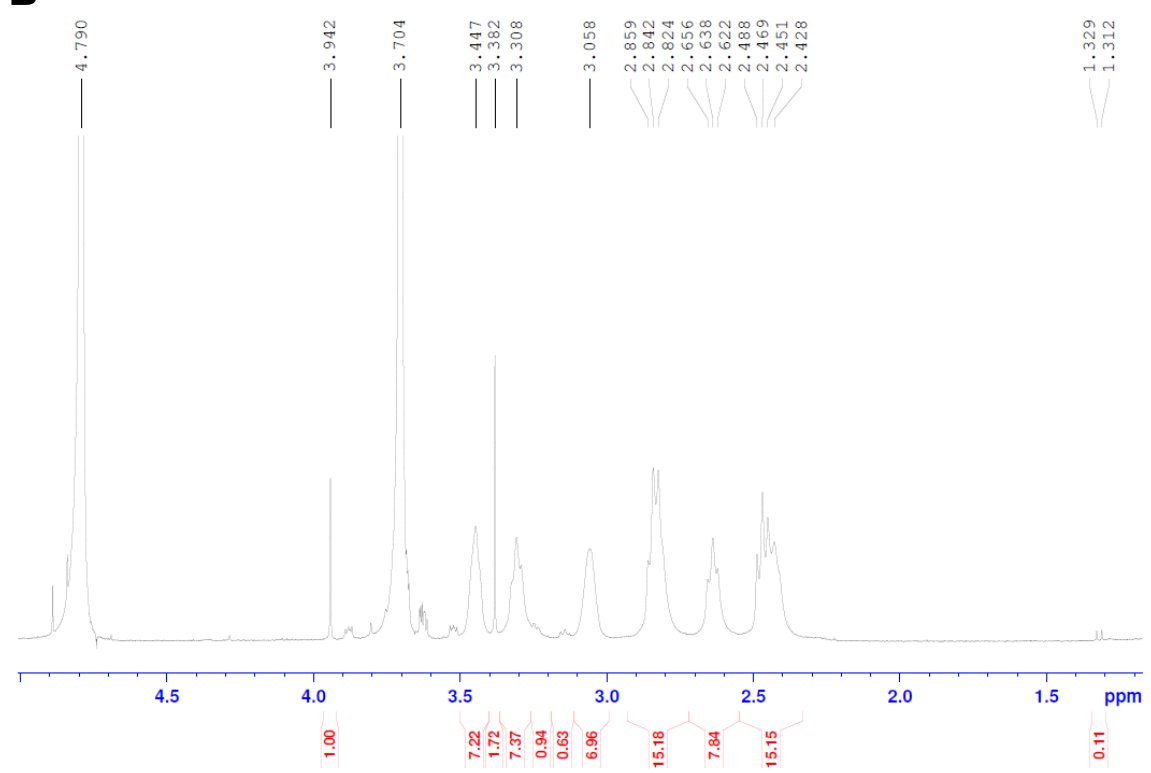

Rua Alfredo Allen, 208 4200-135 Porto Portugal +351 220408800 
C
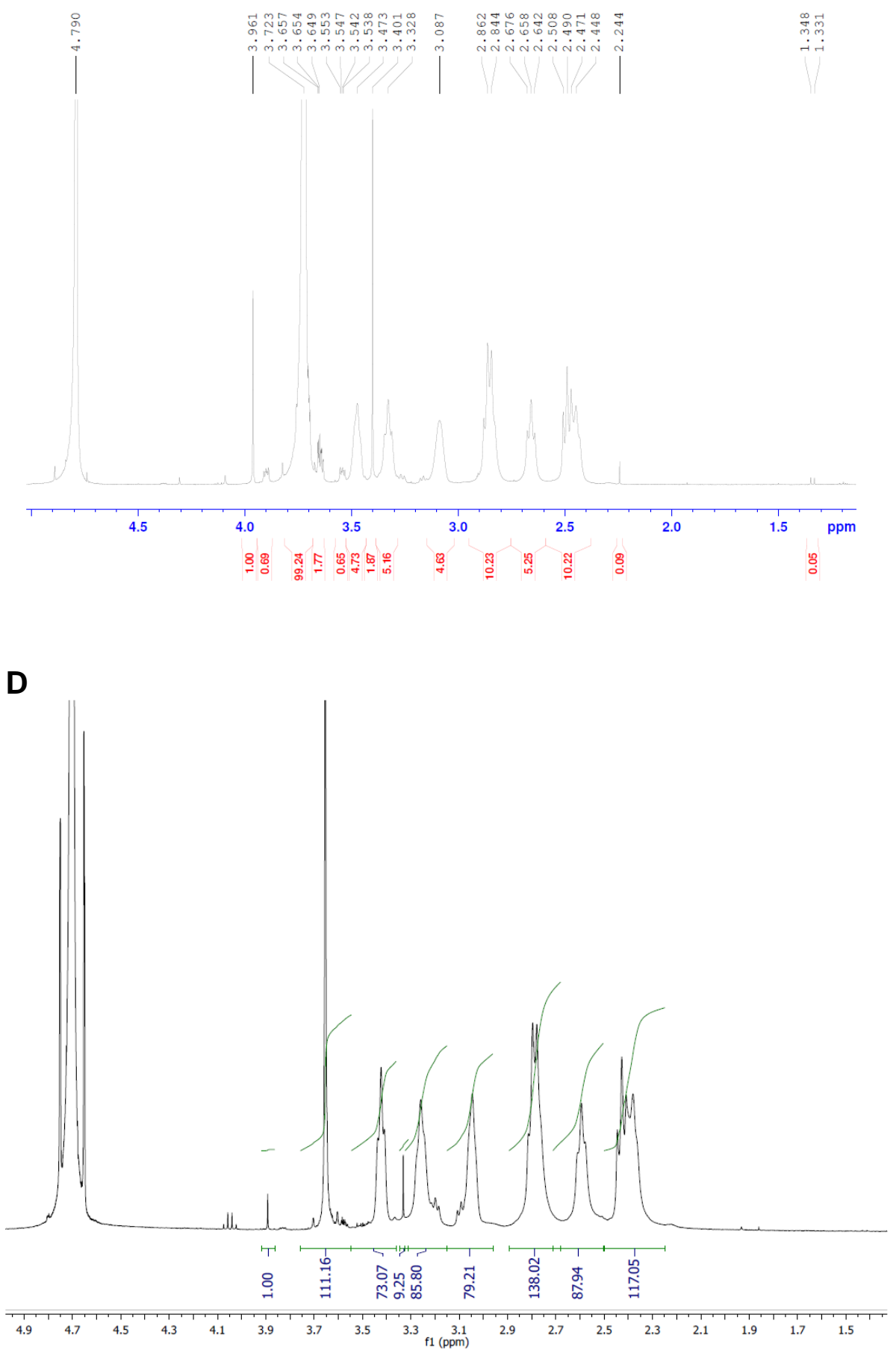

Rua Alfredo Allen, 208 4200-135 Porto Portugal +351 220408800 


\section{E}

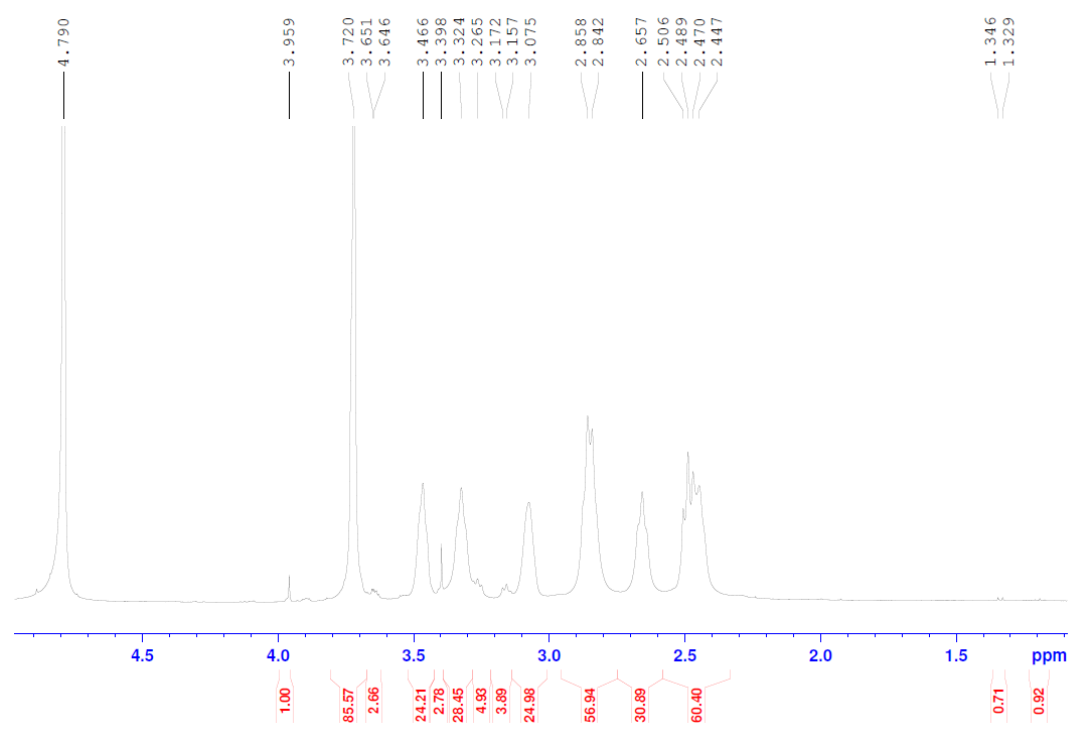

$\mathbf{F}$

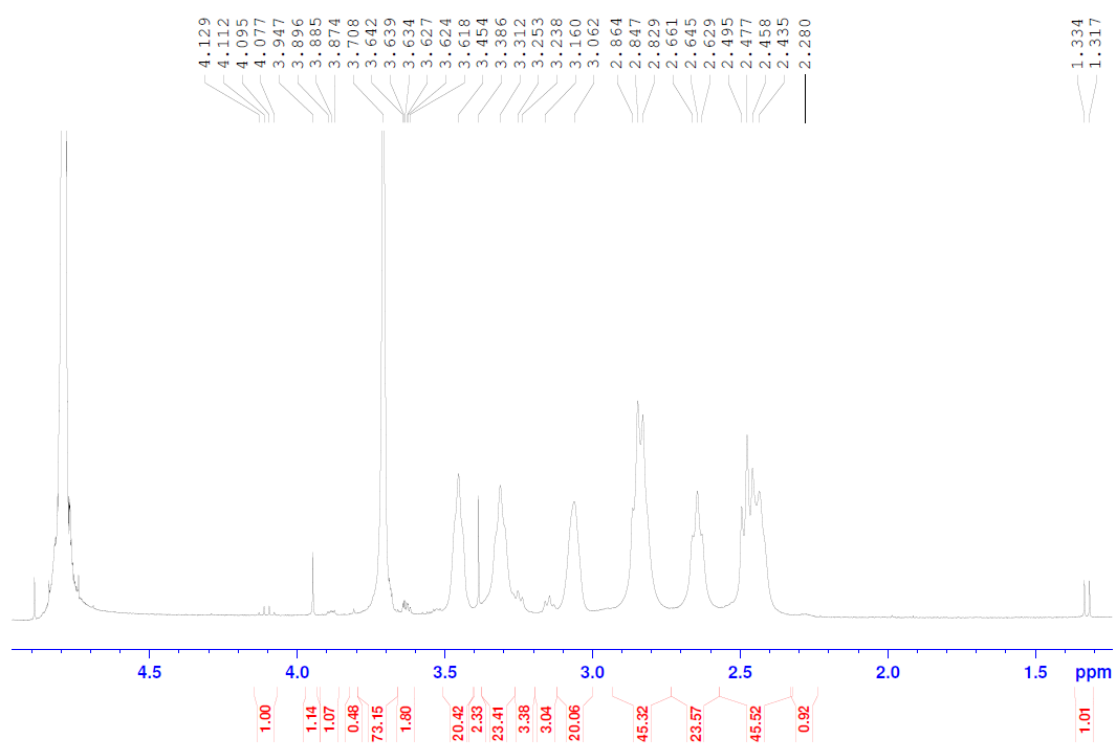

Figure S1. ${ }^{1} \mathrm{H}$ NMR Spectra for G4/G6 PEGylated PAMAM. (A) ${ }^{1} \mathrm{H}$ NMR Spectra of G4 PAMAMRITC-4mPEG. (B) ${ }^{1} \mathrm{H}$ NMR Spectra of G4 PAMAMrITC-8mPEG. (C) ${ }^{1} \mathrm{H}$ NMR Spectra of G4 PAMAMrITC-12mPEG. (D) ${ }^{1} \mathrm{H}$ NMR Spectra of G6 PAMAMrITC-4mPEG. G6 PAMAMRITC8mPEG. (E) ${ }^{1} \mathrm{H}$ NMR Spectra of G6 PAMAMRITC-8mPEG. (F) ${ }^{1} \mathrm{H}$ NMR Spectra of G6 PAMAMRITC-12mPEG. 


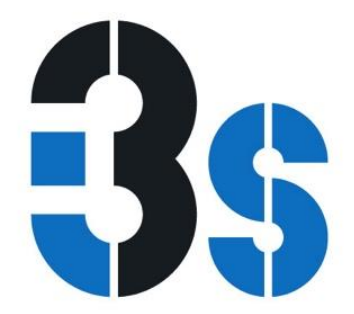

Figure S2.
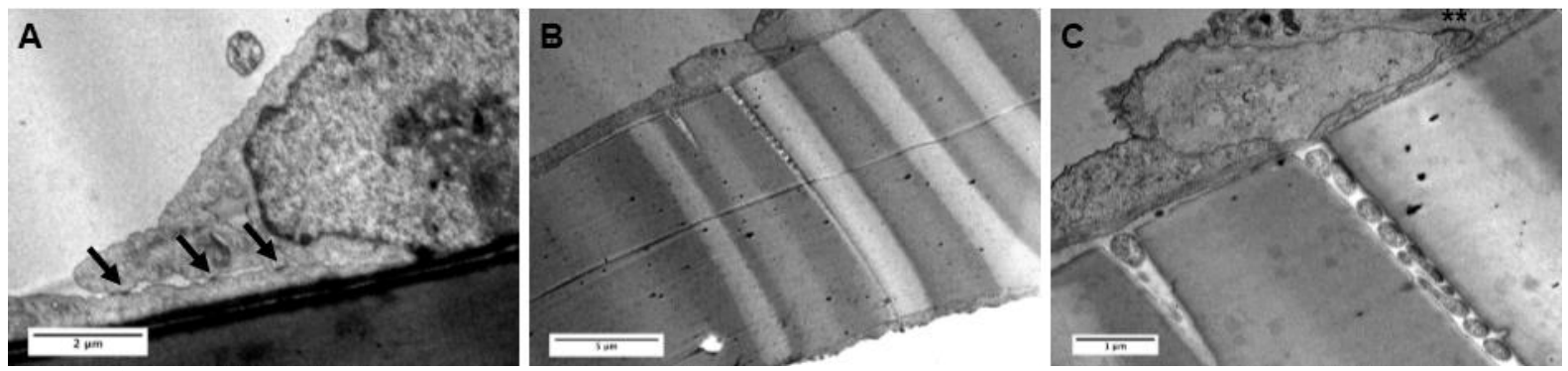

Figure S2. Transmission electron micrographs of bEnd.3 cells co-cultured with rat primary astrocytes on

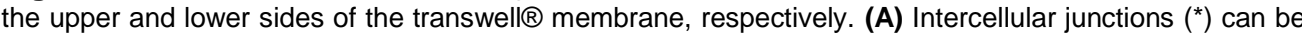
identified between two endothelial cells (electron-dense spots). On (B), typical astrocyte processes can be seen extending (in and out of plane) from the lower side of the membrane through a pore and reaching the endothelial cells on the opposite side, magnified in $\left.[(\mathbf{C})],{ }^{* *}\right)$.

\section{Figure S3.}

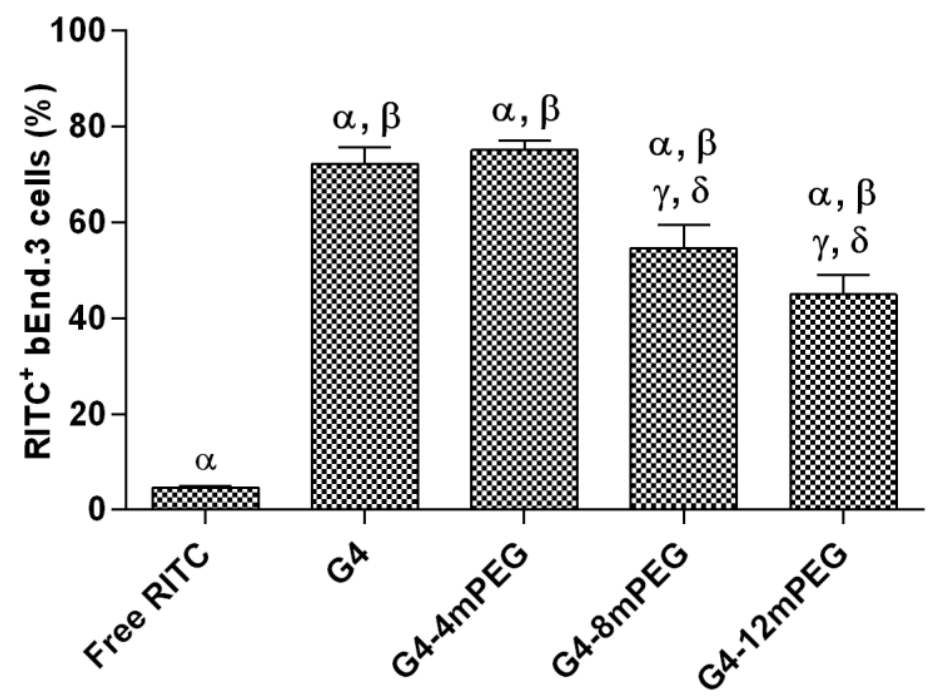

Figure S3. Uptake of G4 PAMAMRITC conjugates by bEnd.3 cells after $4 \mathrm{~h}$ in contact. Results are expressed as mean percentage of RITC positive $\left(\mathrm{RITC}^{+}\right)$cells as detected by flow cytometry. Untreated cells, without PAMAM, were used as a control. Statistical analysis denotes significant differences of each condition versus aControl; $\beta F$ ree RITC; $\gamma G 4 ; \delta G 4-4 m P E G ; n=3$; $\mathrm{p}<0.05)$. 
Figure S4.

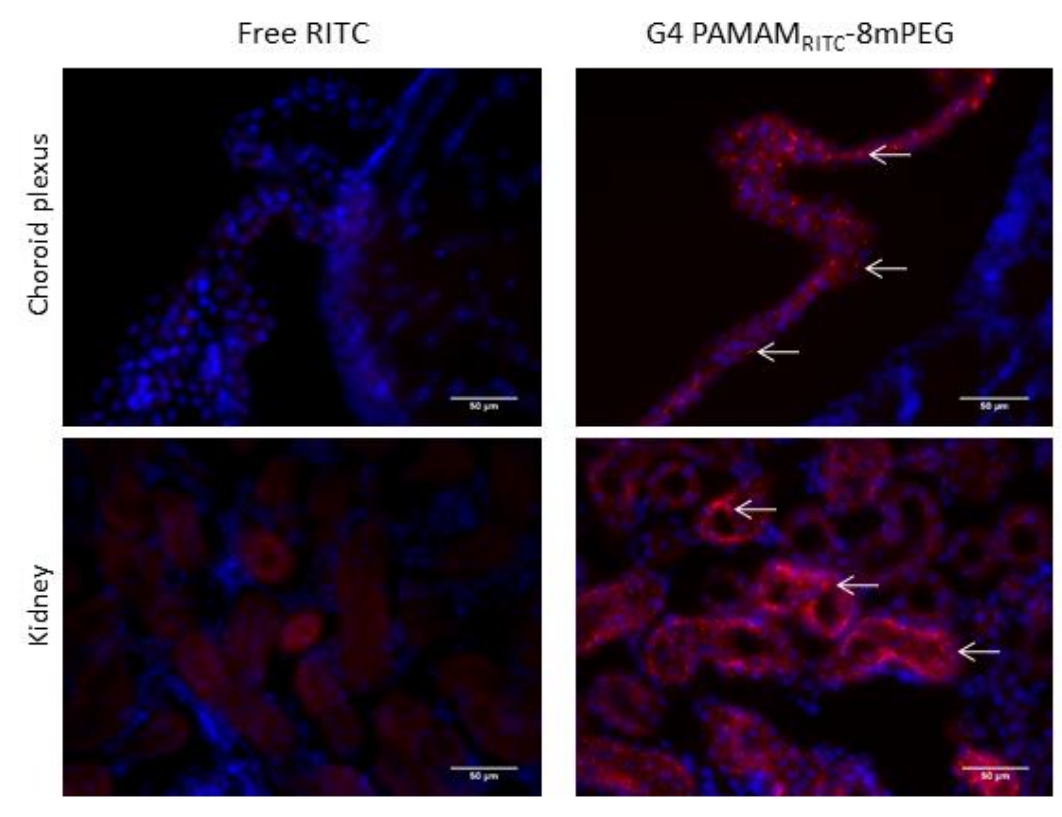

Figure S4. G4 PAMAMRITC-8mPEG tissue distribution. Control free RITC (left images) and PAMAM conjugated with RITC (right images) detection in choroid plexus of the brain (upper images) and kidney (bottom images), $24 \mathrm{~h}$ after i.v. administration. $\mathrm{n}=8$ for each condition and tissue. 